\title{
Assessment of Hopelessness in Older Adults: The Development and Initial Validation of the Hopelessness Inventory for Later Life (HILL)
}

Jeffrey J. Gregg

West Virginia University

Follow this and additional works at: https://researchrepository.wvu.edu/etd

\section{Recommended Citation}

Gregg, Jeffrey J., "Assessment of Hopelessness in Older Adults: The Development and Initial Validation of the Hopelessness Inventory for Later Life (HILL)" (2014). Graduate Theses, Dissertations, and Problem Reports. 661.

https://researchrepository.wvu.edu/etd/661

This Dissertation is protected by copyright and/or related rights. It has been brought to you by the The Research Repository @ WVU with permission from the rights-holder(s). You are free to use this Dissertation in any way that is permitted by the copyright and related rights legislation that applies to your use. For other uses you must obtain permission from the rights-holder(s) directly, unless additional rights are indicated by a Creative Commons license in the record and/ or on the work itself. This Dissertation has been accepted for inclusion in WVU Graduate Theses, Dissertations, and Problem Reports collection by an authorized administrator of The Research Repository @ WVU.

For more information, please contact researchrepository@mail.wvu.edu. 
Assessment of Hopelessness in Older Adults: The Development and Initial Validation of the Hopelessness Inventory for Later Life (HILL)

\title{
Jeffrey J. Gregg
}

\author{
Dissertation submitted \\ to the Eberly College of Arts \& Sciences \\ at West Virginia University \\ in partial agreement of the requirements for the degree of \\ Doctor of Philosophy in \\ Psychology (Clinical)
}

\begin{abstract}
Amy Fiske, Ph.D., Chair
Barry Edelstein, Ph.D.

William Fremouw, Ph.D.

Julie Hicks Patrick, Ph.D.

Ian Rockett, Ph.D.

Department of Psychology
\end{abstract}

\section{Morgantown, WV}

2014

Keywords: Hopelessness, Suicide, Older Adult, Geriatric, Assessment, Psychometrics Copyright 2014 Jeffrey J. Gregg 


\begin{abstract}
Assessment of Hopelessness in Older Adults: The Development and Initial Validation of the Hopelessness Inventory for Later Life (HILL)
\end{abstract}

\title{
Jeffrey J. Gregg
}

Hopelessness has been shown to be a strong, independent risk factor for physical illness, suicidal behavior, and mortality. It is an especially important construct for assessment in later life, as older adults are at an elevated risk of suicide worldwide. Studies have generally supported the use of the Beck Hopelessness Scale (BHS; Beck et al, 1974) with older adults; though, it was not designed with this population in mind. On the other hand, the Geriatric Hopelessness Scale (GHS; Fry, 1984) was constructed specifically for use with older adults, but has demonstrated unstable psychometric properties. In addition, many items on the GHS lack face validity or may be too culturally specific. Both the BHS and the GHS contain items that may be conflated with realistic appraisals of remaining time or physical illness. Based on these characteristics, the creation of a new measure for geriatric hopelessness is warranted. The current study sought to construct and validate a self-report scale for late-life hopelessness that contains future-oriented thematic content relevant to older adults (e.g., legacy, social support, pain) and excludes items that may be inherently biased against older adults or individuals with life-limiting illnesses. Items were drafted based on a literature review and sent to experts in the field of geriatric depression/suicide for revision and to establish content validity. After review, the preliminary version of the Hopelessness Inventory for Later Life (HILL) contained 30 items and utilized a 4point Likert-type response format. A sample of 265 older adults completed a survey battery containing the preliminary HILL, as well as other relevant measures in order to further revise the item content and examine its psychometric properties. The sample included older adults recruited in-person (i.e., from senior centers, a family medicine clinic, churches), through a mailing list, and online via Amazon mTurk (M age=71.1 SD=6.7). An examination of itemresponse characteristics (e.g., skewness) revealed one item as a candidate for deletion. An unrotated principal components analysis was then used to examine unidimensionality and to identify additional items for deletion. Based on these analyses, two viable versions of the scale, the HILL and the HILL-Shortened (HILL-S) were proposed. Both exhibited strong itemresponse characteristics, as well as preliminary evidence of unidimensionality, internal consistency ( $\alpha=.96$ and $\alpha=.89$, respectively), and construct validity. Regarding construct validity, the HILL and the HILL-S were strongly associated with measures of hopelessness (BHS), geriatric depression, perceived burdensomeness, and social support. Moderate correlations were found with suicide risk, anxiety, self-rated health, physical health, and pain interference. The HILL and the HILL-S demonstrated small associations with social desirability and pain frequency. Finally, there was no relation observed between age and either the HILL or the HILL-S. Exploratory analyses provided evidence that both measures functioned as mediators and moderators in the relation between geriatric depression and suicidality, consistent with relevant theories of suicide, whereas the BHS did not. Overall, results from the current study provide preliminary evidence of good psychometric properties for both the HILL and HILL-S. Moreover, in light of findings from mediational and moderational analyses, the current study lends greater support to the HILL and HILL-S in the assessment of late-life hopelessness compared to the BHS. 


\section{Table of Contents}

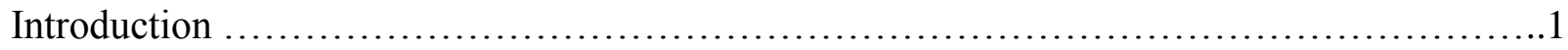

Hopelessness \& Suicidality in Later Life.....................................2

Mediational Analyses.......................................................4

Moderational Analyses.....................................................

Hopelessness as an Independent Risk Factor..................................

Integration of Research Findings with Older Adults..............................8

The Beck Hopelessness Scale................................................10

The Geriatric Hopelessness Scale........................................... 13

Statement of the Problem.................................................. 15

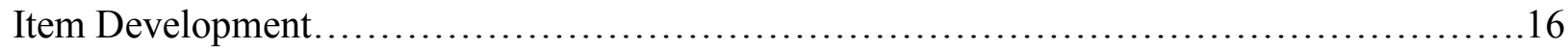

Methods...............................................................

Results and Discussion.................................................... 19

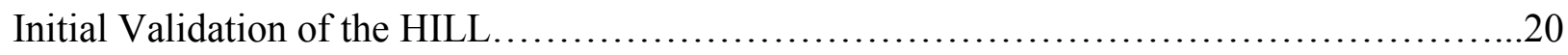

Methods................................................................21

Recruitment and Procedure..............................................21

Participants.....................................................23

Measures............................................................25

Analyses........................................................ 33

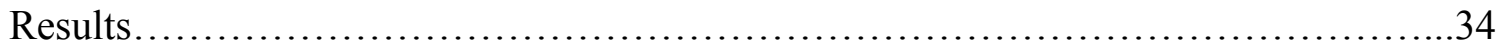

Item Selection........................................................ 35

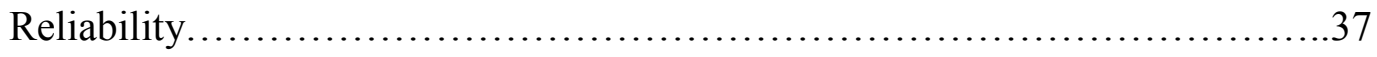

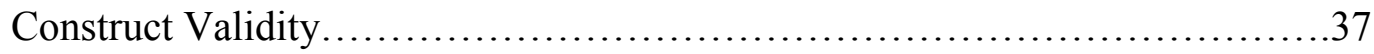




\section{Table of Contents (continued)}

Exploratory Analyses............................................... 38

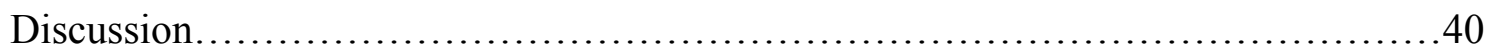

Limitations.......................................................... 47

Conclusion........................................................ 48

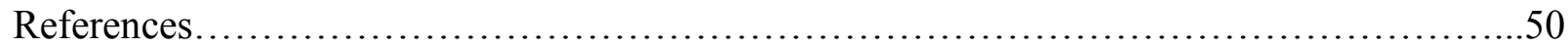

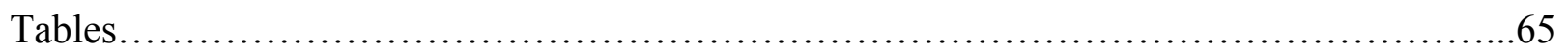

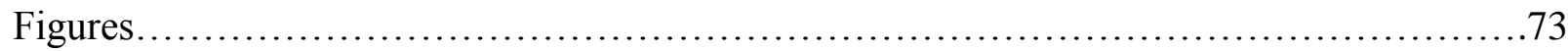

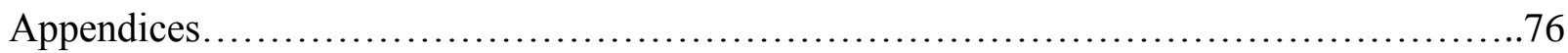


Hopelessness, broadly defined as a system of negative beliefs about one's self and one's future (Stotland, 1969), has garnered a wealth of empirical support as an important construct in psychological assessment and treatment. Hopelessness is more than a symptom of major depression; rather, it has been shown to be a strong risk factor for physical illness (e.g., Anda et al., 1993), suicidal behavior (e.g., Beck, Brown, Berchick, Stewart, \& Steer, 1990), and mortality (e.g., Everson et al., 1996). In fact, hopelessness has been found to be an independent risk factor for these negative outcomes controlling for overall depressive symptoms (e.g., Everson et al., 1996). Considering the negative health implications associated with this psychological construct, accurate assessment of hopelessness represents a critical public health issue. Hopelessness is an especially salient risk factor for suicidal behavior. Indeed, Aaron Beck and other cognitive-behavioral theorists have proposed that hopelessness is the link between major depression and suicidal behavior (Beck, Kovacs, \& Weissman, 1975). Beck and colleagues' theory suggests that individuals suffering from depression do not become suicidal until they develop maladaptive cognitions related to the notion that their situation will remain stable. Likewise, proponents of the Interpersonal Theory of Suicide contend that hopelessness about one's social situation (e.g., thwarted belongingness, perceived burdensomeness) results in suicidal ideation (Van Orden et al., 2010; Cukrowicz et al., 2013). Abramson, Metalsky, and Alloy (1989) have even proposed the existence of a hopelessness subtype of depression, in which hopelessness is a prominent symptom and suicidal ideation is more likely.

Research conducted with younger adults and mixed age samples has overwhelmingly supported the hypothesis that hopelessness is a prominent risk factor for suicide (Conner, Duberstein, Conwell, Seidlitz, \& Caine, 2001). For instance, one measure of hopelessness, the Beck Hopelessness Scale (BHS; Beck, Weissman, Lester, \& Trexler, 1974), has demonstrated 
excellent sensitivity, correctly identifying over $90 \%$ of eventual suicides in two studies (Beck, Steer, Kovacs, \& Garrison, 1985; Beck et al., 1990). The specificity of the BHS is much lower (e.g., 41\%; Beck et al., 1990); however, this is the case for most risk factors of suicide. Notably, most studies with younger adults support a mediational model of hopelessness on the relation between depression and suicidal behavior. These include studies examining suicidal ideation (e.g., Dyer \& Kreitman, 1984; Wetzel, Margulies, Davis, \& Karam, 1980; Beck, Steer, Beck, \& Newman, 1993), suicide attempts (e.g., Beck et al., 1975), and death by suicide (e.g., Conner et al., 2001; Beck et al., 1985; Beck et al., 1990) as the dependent variable.

\section{Hopelessness \& Suicidality in Later Life}

Hopelessness may be especially important to consider as a risk factor for suicide in later life, as there is some evidence that hopelessness is more prevalent among older adults compared to younger adults (Greene, 1981). The identification of risk factors for suicide in later life is crucial, given that worldwide rates of suicide among older adults are high (Bertolote, 2001). Furthermore, suicidal behavior has a much higher degree of lethality in later life compared to earlier life (Chan, Draper, \& Banerjee, 2007), thereby decreasing the window of opportunity for intervention.

A strong and significant relation between hopelessness and suicidal ideation has been found in a variety of older adult populations, including medical outpatients (Britton et al., 2008; Hill et al., 1988), community-dwelling older adults (Ron, 2004; Neufeld, O’Rourke, \& Donnelly, 2010), primary care patients (Cukrowicz et al., 2013), long-term care residents (Meeks \& Tennyson, 2003; Ron, 2004; Uncapher, Gallagher-Thompson, Osgood, \& Bongar, 1998), terminally ill individuals (Chochinov et al., 1998; Breitbart et al., 2000), and mixed samples (Heisel \& Flett, 2005; Neufeld \& O’Rourke, 2009). At least two studies with treatment-seeking 
older adults also have found higher levels of hopelessness among individuals with prior suicide attempts (Rifai et al., 1994; Szanto, Reynolds, Conwell, Begley, \& Houck, 1998). Moreover, Szanto and colleagues (1998) found that higher levels of hopelessness endured after treatment for late-life depression among suicide attempters compared to suicide ideators and non-suicidal patients.

There is a paucity of research examining the relation between hopelessness and death by suicide specifically among older adults. However, a recent case-controlled, psychological autopsy study found that decedents' statements of hopelessness within the last 12 months of life significantly predicted death by suicide among individuals aged 60 and over (De Leo, Draper, Snowdon, \& Kõlves, 2013). Based on the findings of these studies, there is little doubt that a strong association exists between hopelessness and suicidal behavior in later life.

Studies examining the tripartite relation between hopelessness, depression, and suicidality in later life have been less clear. At least nine studies with older adults have included multivariate analyses with these three variables (Breitbart et al., 2000; Chochinov et al., 1998; Cukrowicz et al., 2011; Hill et al., 1988; Meeks \& Tennyson, 2003; Neufeld \& O’Rourke, 2009; Neufeld, O’Rourke, \& Donnelly, 2010; Uncapher et al., 1998; Trentesaeu et al., 1989). Most have corroborated findings with younger adult samples that showed hopelessness to be associated with suicidal ideation independent of depressive symptoms. However, three studies did not provide support for this model; furthermore, the role of late-life hopelessness in this tripartite relation is unclear (i.e., is it a mediator, moderator, or neither?). Each of the studies examining the multivariate relations between hopelessness, depression, and suicidal ideation among older adults is briefly reviewed in the following sections. Studies that examined mediational models are reviewed first, followed by those that tested moderational models. 
Finally, all other studies that included multivariate analyses with hopelessness, depression, and suicidality, but did not directly test for mediation/moderation are discussed.

\section{Mediational Analyses}

To date, only two studies with older adults have tested the mediational model of hopelessness in the relation between depression and suicidality (as proposed by Beck and colleagues, 1975). Chochinov and colleagues (1998) conducted one such study with 196 terminally ill cancer patients with a mean age of 71 years $(S D=10.7)$. Assessment measures included the Beck Depression Inventory-Short Form (BDI-SF; Beck \& Beck, 1972) and the Schedule for Affective Disorders and Schizophrenia (SADS; Endicott \& Spitzer, 1978). A hopelessness variable was created by combining one item from the BDI-SF ("pessimism") and one item from the SADS ("discouragement, pessimism, hopelessness"). Suicidal ideation was derived similarly; one item from the BDI-SF ("self-harm") was combined with one item from the SADS (“suicidal tendencies"). Pearson's product-moment correlational analysis revealed a moderate bivariate relation between hopelessness and suicidal ideation $(r=.46)$. Furthermore, a one-tailed t-test revealed that hopelessness was more strongly correlated with suicidal ideation than with depression, $t(193)=1.85, \mathrm{p}<.05$. Multiple regression analyses demonstrated that hopelessness mediated the relation between depressive symptoms and suicidal ideation in terminally ill older adults.

The second study that examined a mediational model was conducted by Meeks and Tennyson (2003). Their sample was comprised of 39 female nursing home residents $(\mathrm{M}$ age $=$ 84.1, SD =6.9) without significant cognitive impairment. The authors sought to clarify whether hopelessness moderated or mediated the relation between depressive symptoms and suicide ideation. Assessment measures included the Geriatric Hopelessness Scale (GHS; Fry, 1984), the 
Geriatric Depression Scale (GDS; Yeasavage et al., 1983), and the Beck Scale of Suicide Ideation (SSI; Beck, Kovacs, \& Weissman, 1979). Overall, results demonstrated a strong bivariate association between hopelessness and suicidal ideation $(\mathrm{r}=0.55, \mathrm{p}<.01)$. Hierarchical regression analyses indicated that hopelessness mediated the relation between depressive symptoms and suicide ideation. The reverse relation (i.e., that depression mediated hopelessness and suicide ideation) was not supported. Furthermore, there was not a significant interaction between hopelessness and depressive symptoms in predicting suicidal ideation.

Though findings from both Chochinov et al. (1998) and Meeks and Tennyson (2003) supported the mediational model posited by Beck and colleagues (1975), there were limitations with each study. For instance, Chochinov and colleagues did not utilize well-validated measures of hopelessness or suicidal ideation. Furthermore, the sample utilized by Meeks and Tennyson included only women, which represents a threat to external validity.

\section{Moderational Analyses}

As summarized in the prior section, Meeks and Tennyson (2003) did not find support for a moderational model of hopelessness on the relation between depression and suicidality. However, this study had a small sample size $(n=39)$; thus, it may have been underpowered to detect moderation if it was present. Only one other study has examined a moderational model in older adults. Whereas Meeks and Tennyson (2003) examined the hopelessness-depressionsuicide ideation relationship exclusively among women, Uncapher, Gallagher-Thompson, Osgood, and Bongar (1998) examined the same relationship in institutionalized older men. Their sample was comprised of 60 males, including 30 nursing home residents $(\mathrm{M}$ age $=76, \mathrm{SD}=$ 10.4) and 30 psychiatric inpatients ( $\mathrm{M}$ age $=69, \mathrm{SD}=8.1$ ). Like Meeks and Tennyson (2003), Uncapher et al. also utilized the SSI, the GHS, and the GDS. Though nursing home and 
psychiatric inpatient settings are qualitatively different, the authors suggested that combining these samples allowed for greater variability and a broader age range. Furthermore, no differences were found by setting in the major study variables (i.e., depressive symptoms, hopelessness, suicidal ideation). Using the combined sample, the bivariate association between hopelessness and suicidal ideation was strong $(r=.53)$, but not as strong as in other studies with institutionalized older adults (e.g., Ron, 2004). In addition, hopelessness explained only $1 \%$ of additional variance over depressive symptoms in predicting suicidal ideation. Nevertheless, a significant interaction between depression and hopelessness in predicting suicidal ideation was found. A three-way interaction between hopelessness, depressive symptoms, and setting also was tested, but was not significant, suggesting that this relation did not differ between the nursing home and the psychiatric setting.

In interpreting the results and implications of Uncapher and colleagues' (1998) study, there are number of limitations to consider. First, despite the fact that the implications are discussed in terms of their application to "older adults," the sample only included institutionalized older men. Second, the two items related to hopelessness on the GDS were not removed from the analysis. Though this may have little effect on the overall conclusions drawn from the study, removing these two items would reduce overlap between the GDS and the GHS. Third, the authors reported that depression moderated the relation between hopelessness and suicidal ideation. However, given that hopelessness is often considered a symptom of depression (and not vice-versa) and depression was most strongly associated with suicidal ideation in this study, it may have been more logical to conceptualize hopelessness as a moderator of the relation between depressive symptoms and suicidal ideation. No follow-up analyses (e.g., simple slopes) were utilized to characterize the interaction between depression and hopelessness. 


\section{Hopelessness as an Independent Risk Factor for Late-Life Suicidality}

As noted previously, the majority of studies examining depression, hopelessness, and suicidality among older adults have supported hopelessness as an independent risk factor. Results from Chochinov and colleagues' (1998) study of terminally ill older adults and Meeks and Tennyson's (2003) study of nursing home residents already have been detailed. Breitbart and colleagues (2000) found that both hopelessness and depressive symptoms were significantly and independently related to "desired for hastened death" in a terminally ill population. Desire for hastened death is conceptualized as a unifying construct encompassing suicidal ideation and requests for assisted suicide or euthanasia (Rosenfeld et al., 2006). In a sample of older adults seeking depression treatment, Hill et al. (1988) found that depressive symptoms, hopelessness, and self-reported health ratings all independently and significantly predicted suicidal ideation. Two studies conducted with a sample of 117 community-dwelling older adults also have provided support for the independent contribution of hopelessness to suicidality in later life. Using canonical correlation analysis, Neufeld and O’Rourke (2009) found that hopelessness explained significant variance in all four subscales of a geriatric suicide ideation scale.

Similarly, Neufeld, O’Rourke, and Donnelly (2010) found that two dimensions of hopelessness, "powerlessness" and "negative future expectancies," significantly predicted suicidal ideation independent of overall depressive symptoms.

Despite these findings, three studies with older adults have not supported hopelessness as an independent risk factor of suicidal ideation. Of these, two were conducted with older psychiatric inpatients (Trenteseau et al., 1989; Uncapher et al., 1998). Uncapher and colleagues’ study of institutionalized men has been described previously. Trenteseau, Hyer, Verenes, and Warsaw (1989) examined 50 individuals aged $\geq 55$ years $(M=60.5)$ who were institutionalized 
due to a variety of psychiatric disorders (e.g., depression, schizophrenia, adjustment disorder). Their results indicated that, though hopelessness was associated with a number of other variables (e.g., greater depressive symptoms, poorer cooperation, poorer communication), it was not associated with prior suicide attempts or suicidal ideation over and above depressive symptoms. Moreover, in a study of community-dwelling older adults, Cukrowicz and colleagues (2011) found that neither overall depressive symptoms nor hopelessness was significantly related to suicidal ideation after controlling for loneliness and perceived burdensomeness in communitydwelling older adults.

\section{Integration of Research Findings with Older Adults}

Considering the results of studies examining late-life hopelessness, depression, and suicidality, it is unclear whether hopelessness is an independent risk factor for suicidal behavior. If hopelessness is an independent risk factor, it also is unclear whether it acts as a mediator (e.g., Meeks \& Tennsyon, 2003), a moderator (Uncapher et al., 1998), or both in the relation between depression and suicidal ideation in later life.

There are many possible explanations for the inconsistent findings with hopelessness, depression, and suicidality among older adults. The importance of hopelessness in predicting suicidal behavior may vary by population. For instance, it is possible that hopelessness may be less relevant for suicidal ideation among older psychiatric inpatients (e.g., Trenteseau et al., 1989; Uncapher et al., 1998) compared to other populations of older adults (e.g., communitydwelling, treatment-seeking). Based on the findings of Cukrowicz and colleagues (2011), it also is possible that interpersonal variables (e.g., perceived burdensomeness and loneliness) may be more salient risk factors for suicidal behavior compared to hopelessness and other depressive symptoms. This hypothesis would be consistent with the socioemotional selectivity theory 
(Carstensen \& Mikels, 2005), which posits that people hone their social networks to maximize emotional rewards as future time perspective decreases. Thus, social networks are smaller in later life, but more emotional capital is at stake. Nonetheless, this logic would suggest that hopelessness about one's social situation (i.e., social hopelessness) is an important factor to consider in suicidal behavior, as proposed by Van Orden (2010). To date, no study has examined the possible interaction between hopelessness and social connectedness in predicting suicidal ideation.

The mixed findings with regard to depression, hopelessness, and suicidality also could be due to a lack of clarity in the construct of hopelessness. For instance, most definitions of hopelessness involve negative expectancies toward the future (Beck et al., 1974; Weishaar \& Beck, 1992; Abramson et al., 1989). However, for many older adults, it is possible that "negative expectancies toward the future" may reflect a realistic time perspective associated with non-restorable cognitive/physical decline or terminal illness. Chochinov and colleagues (1998) highlight the importance of disentangling a hopeless prognosis from a hopeless cognitive style, which may be an especially important concept for older adults.

Furthermore, the inconsistent findings regarding hopelessness, depression, and suicidality in later life may be due, in part, to the limited utility of current assessment instruments for hopelessness with older adults. Virtually all of the studies that have examined hopelessness in later life have used either the Geriatric Hopelessness Scale (GHS) or the Beck Hopelessness Scale (BHS). For instance, the GHS has been utilized with nursing home residents (Meeks \& Tennyson, 2003; Uncapher et al., 1998), psychiatric inpatients (Trenteseau et al., 1989; Uncapher et al., 1998) and mixed samples (Heisel \& Flett, 2005). The BHS has been examined among outpatients (Britton et al., 2008; Hill et al., 1988), community-dwelling adults (Cukrowicz et al., 
2011; Ron, 2004), terminally ill individuals (Breitbart et al., 2000), nursing home residents (Ron, 2004), and mixed samples (Heisel \& Flett, 2005; Neufeld \& O’Rourke, 2009; Neufeld et al., 2010). There are unique limitations associated with each of these measures, including conceptual issues (e.g., disentangling hopeless prognoses and hopeless cognitions) and psychometric properties.

\section{The Beck Hopelessness Scale}

The BHS is a 20-item true/false measure intended to assess an individual's degree of hopelessness about the future (Beck, Weissman, Lester, \& Trexler, 1974). The scale includes nine items that were revised from a test of attitudes about the future (Heimburg, 1961) and 11 items drawn from pessimistic statements made by psychiatric inpatients (e.g., "The future seems vague and uncertain to me"). The nine items drawn from Heimbug (1961) are framed positively and, thus, are reverse-scored (e.g., "In the future, I expect to succeed in what concerns me the most”). Beck and colleagues' (1974) initial analysis of the measure demonstrated excellent internal consistency $(\alpha=.93)$ in a sample of 294 suicide attempters. Furthermore, construct validity was established via strong correlations with clinician ratings of hopelessness among 23 outpatients ( $\mathrm{r}=.74)$ and 62 hospitalized inpatients ( $\mathrm{r}=.62)$. Using the sample of 294 suicide attempters, Beck et al. conducted a principal components analysis with varimax rotation and specified a three-factor solution, which accounted for $53.5 \%$ of the variance. These factors were labeled (1) feelings about the future, (2) loss of motivation, and (3) future expectancies. Subsequent studies, however, have not been able to replicate a three-factor solution. For instance, Aish and Wasserman (2001) subjected the BHS to confirmatory factor analyses using a sample of 324 suicide attempters. Neither a three-factor nor a two-factor solution provided adequate fit for the data (Aish \& Wasserman, 2001). Despite the inconsistent findings with 
regard to factor structure, the BHS has demonstrated high sensitivity (>90\%) in predicting eventual suicide using a cutoff score of 10 or higher (Beck et al., 1985; Beck et al., 1990).

Two studies have examined the psychometric properties of the BHS among older adults. Hill, Gallagher, Thompson, and Ishida (1988) evaluated the BHS in a sample of 120 adults (M age $=66.9, \mathrm{SD}=5.7$ ) seeking treatment for major depression. Results from this study demonstrated good internal consistency $(\alpha=.84)$ and construct validity with depressed older adults. Specifically, it was significantly correlated with the Beck Depression Inventory $(r=.41)$ and poorer self-rated health $(r=.25)$, and was not related to age or level of education. Regarding age, however, the range was somewhat restricted in this study (ages 58-82) with primarily young-old adults. Utilizing an exploratory factor analysis, Hill and colleagues specified a threefactor structure of the BHS, with the following themes: (1) optimism about the future, (2) giving up, and (3) future planning. Each factor was significantly related to suicide ideation, but when considered together, only "giving up" emerged as a significant, independent predictor, $F(1,118)$ $=15.0, \mathrm{p}<.001$. Interestingly, the bivariate correlation between the full BHS and suicidal ideation was not reported. Nevertheless, in a stepwise multiple regression analysis, depressive symptoms, hopelessness, and self-reported health ratings all independently and significantly predicted suicidal ideation (hopelessness: $\left.R^{2}=.24, F(2,117)=18.0, \mathrm{p}<.001\right)$.

Neufeld, O'Rourke, and Donnelly (2010) sought to validate an alternate form of the BHS with a mixed sample of older adults. Specifically, the authors cited limitations associated with the traditional true/false format of the scale and instead proposed a four-point, Likert-type response format for the BHS similar to that of the Center for Epidemiologic Studies- Depression scale (i.e., where $0=$ rarely to none and $3=$ most days; Radloff, 1977). Results from their exploratory factor analysis supported a two-factor structure for the BHS labeled 
"Powerlessness/Disappointment" and "Negative Future Expectancies." The two subscales both demonstrated adequate internal consistency ( $\alpha$ 's $=0.92$ and 0.86 respectively) and both independently predicted suicide ideation, even after controlling for socio-demographic factors (e.g., age, sex, education), perceived health, and depressive symptoms ( $\beta$ 's $=0.36$ and 0.30 , $\mathrm{p}<.01$ respectively). Other than the factor analysis, no additional analyses were reported involving the full BHS.

Results from these psychometric analyses of the BHS provide some, albeit limited, evidence to support its use among older adults. Notably, the findings from factor analyses differed substantially between Hill et al. (1988) and Neufeld et al. (2010). For instance, Neufeld and colleagues (2010) found that the first item ("I look forward to the future with hope and enthusiasm") did not load onto either factor, whereas Hill et al. (1988) demonstrated this same item to have the single strongest loading on their first component (.70). Furthermore, Hill and colleagues specified a three-factor solution versus the two-factor solution identified by Neufeld et al. These stark differences in factor structure may be due to the varied response formats for the BHS used between these two studies. Using the standard true/false format of the tool, the three-factor structure specified by Hill and colleagues was remarkably similar to the original factor structure reported by Beck and colleagues (1974). This finding lends initial support for age invariance in the BHS. In addition, the fact that two exploratory factor analytic studies specified different factor solutions does not necessarily imply contradictory findings. Confirmatory factor analyses would be required to address this conceptual issue.

Other studies that used the BHS with older adults also have attested to the measure's internal consistency and construct validity. Ron (2004) reported an alpha of 0.86 in a combined sample of community-dwelling older adults $(\mathrm{n}=227)$ and nursing home residents $(\mathrm{n}=91)$. 
Regarding validity, the BHS was strongly correlated with the Beck Depression Inventory (BDI;

Beck et al., 1979) and the Scale for Suicide Ideation (SSI; Beck et al., 1979) in both subsamples. Though Ron (2004) did not compare the relative strength of the relation between the BHS and the SSI between the two subsamples, a Fisher r-to-z showed that the correlation between hopelessness and suicidal ideation was significantly stronger among nursing home residents $(\mathrm{r}=.94)$ compared to the community-dwelling sample $(\mathrm{r}=.86)(\mathrm{z}=3.53, \mathrm{p}=.0002)$. Cukrowicz et al. (2011) used the BHS in a study of 105 older primary care patients $(\mathrm{M}=70.89, \mathrm{SD}=7.63)$. They also found adequate internal consistency $(\alpha=.86)$. Moreover, the BHS was strongly correlated with measures of depression, loneliness, perceived burdensomeness, and suicidal ideation, and was inversely correlated with a measure of overall health (Cukrowicz et al., 2011). The BHS was not significantly associated with age in their study; however, this study also included a limited age range.

Despite the relatively well-established psychometric properties of the BHS among older adults, there are limitations for its use with this population. As noted by Heisel and Flett (2005), the BHS was not designed with older adults in mind. Thus, it does not contain age-related thematic content that may be helpful in guiding interventions with older adults. The omission of such age-relevant content in the BHS may increase the risk of not detecting of hopelessness in later life if it is present. Examples of future-oriented themes that may be especially important to older individuals include death, pain, physical functioning, cognitive functioning, legacy, independence, and meaning in life.

\section{The Geriatric Hopelessness Scale}

A second measure that is commonly used to assess hopelessness in later life is the Geriatric Hopelessness Scale (GHS; Fry, 1984). The GHS is a 30-item true/false measure 
designed to assess hopelessness specifically among older adults. Items were created and refined based on pessimistic themes that emerged from a factor analysis of interviews conducted with 60 community-dwelling older adults with sub-threshold symptoms of depression. Fry reported an initial Cronbach's alpha of 0.69, which was described as low, but acceptable. However, contemporary conventions of internal consistency propose that $\alpha \geq 0.70$ is the target statistic (DeVellis, 2012). Fry also specified a four-factor structure, including (1) physical/cognitive abilities, (2) personal/interpersonal worth and attractiveness, (3) spiritual faith and grace, and (4) nurturance, respect, and remembrance. Construct validity for the GHS was established via significant correlations with measures of geriatric depression and self-esteem (Fry, 1984). Unfortunately, subsequent psychometric analyses of the GHS have demonstrated poor item variance, a restricted range of scores, low internal consistency, and an unstable factor structure (Hayslip, Lopez, \& Nation, 1991; Heisel \& Flett, 2005). Some items on the GHS also appear to lack face validity (e.g., item 24: "I can make myself attractive") or may be too culturally specific (e.g., item 12: "God is kind and merciful"). Heisel and Flett (2005) conducted a thorough psychometric analysis of the GHS and ultimately sought to revise the measure. They included both the GHS and the BHS, which allowed for direct comparison between the two measures of hopelessness. They found that the GHS did not differentiate between psychiatric patients versus non-patients. Poor item endorsement on the GHS was pervasive, as 22 of the 30 items were endorsed by $20 \%$ or fewer of the participants. Even when item endorsement analyses were restricted to mental health patients, over one-half of the items were endorsed by $20 \%$ or fewer of the participants (Heisel \& Flett, 2005). In terms of item acceptability, 20\% of participant endorsement has been proposed as the lower limit (Streiner \& Norman, 2003). 
Heisel and Flett also conducted an exploratory factor analysis of the GHS and specified a three-factor solution, including factors related to (1) fatalistic, (2) interpersonal, and (3) spiritual dimensions of hopelessness. The third factor, which was comprised of items related to spirituality (e.g., "God will forgive me for my sins"), was not significantly correlated with measures of geriatric suicide ideation $(r=.17)$, geriatric depression $(r=.10)$, or social hopelessness $(r=.09)$, suggesting poor construct validity of the factor (Heisel \& Flett, 2005). Moreover, Heisel and Flett did not replicate the four-factor solution initially proposed by Fry (1984).

Given the limitations associated with the full GHS, Heisel and Flett (2005) attempted to derive a "suicide risk" subscale by examining item-level correlations with the Geriatric Suicide Ideation Scale (GHS; Heisel \& Flett, 2006). Eleven of the 30 GHS items had significant correlations with the GSIS and were selected for inclusion in the GHS-Suicide Risk Scale. However, even after revising the measure in this fashion, the BHS still demonstrated an equivalent, if not stronger, correlation with the GSIS compared to the GHS-Suicide Risk Scale ( $r=69$ and $r=.64$, respectively; Heisel \& Flett, 2005). Overall, the findings presented in Heisel and Flett (2005) provided greater support for the use of the BHS with older adults, despite the fact that it was not designed explicitly for use in this population.

\section{Statement of the Problem}

Over the years, hopelessness in later life has been found to be a risk factor for suicidal behavior (e.g., Szanto et al., 1998) and all-cause mortality (Stern, Dhanda, \& Hazuda, 2001). Research with younger adults has consistently found hopelessness to be a risk factor for suicidal behavior independent of depression. However, because suicidal behaviors in later life have been shown to differ from those in early and mid-life (e.g., firearm use; Conwell et al., 2002), it 
cannot simply be assumed that findings related to hopelessness in younger adults generalize to older populations. Research findings have unanimously supported a significant association between hopelessness and suicidal ideation in older adults. Yet, the literature is less clear regarding the relative strength of hopelessness as a predictor of suicidal ideation in later life when depression is also considered.

Inconsistent findings with regard to depression, hopelessness, and suicidality may be partially attributable to the limited utility of available instruments with older adults. Studies have generally supported the use of the BHS with older adults; though, it was not designed with this population in mind. On the other hand, the GHS was constructed specifically for use with older adults, but has demonstrated unstable psychometric properties (e.g., poor item variance, low internal consistency, unstable factor structure). In addition, many items on the GHS lack face validity or may be too culturally specific. Both of these measures contain items that may be conflated with realistic appraisals of remaining time or physical illness (e.g., BHS: "I can’t imagine what my life will be like in 10 years;" GHS: "There are many different foods and medicines to restore my energy"). Based on these characteristics and findings, the creation of a new measure for geriatric hopelessness is warranted. The current study sought to construct and validate a self-report scale for late-life hopelessness that contains future-oriented thematic content relevant to older adults and excludes items that may be inherently biased against older adults or individuals with life-limiting illnesses.

\section{Item Development}

The scale constructed in the present study is titled the "Hopelessness Inventory for Later Life" (HILL). The purpose of the HILL is to assess hopelessness among older adults and individuals with life-limiting health conditions. Items were designed to avoid pitfalls associated 
with current measures of hopelessness, which have either demonstrated poor psychometric properties (e.g., the GHS) or are not tailored for older adults or individuals with decreased future time perspective (e.g., BHS). For instance, the BHS contains the following item: "I have enough time to accomplish the things I most want to do."

\section{Methods}

Experts in psychological assessment and scale construction stress the importance of outlining a working definition of the target construct prior to drafting items (Clark \& Watson, 1995; Haynes, Richard, \& Kubany, 1995). Prominent researchers of hopelessness (e.g., Beck) have utilized the broad definition put forth by Stotland (1969), who defined hopelessness as a system of negative beliefs pertaining to one's future and one's self. Specifically, hopelessness is characterized by a pessimistic cognitive style (Beck, 1963) and, regarding the self, a sense of helplessness or powerlessness (Neufeld et al., 2010) as an agent of change in one's future. Thus, items drafted for the HILL (Appendix A) were based on Stotland's (1969) general definition of hopelessness (i.e., negative future expectancies), as well as future-oriented themes specific to later life that have emerged from the research literature. Such themes included dignity (e.g., Webster \& Bryan, 2009), social connectedness (e.g., perceived burdensomeness; Cukrowicz et al., 2011), engagement with life (e.g., Rowe \& Kahn, 1997), pain (e.g., Chan, Hadjistavropoulos, Carleton, \& Hadjistavropoulos, 2012), disability, (e.g., Berlau, Corrada, Peltz, \& Kawas, 2012), physical illness (e.g., Gallo et al., 2005), cognitive decline (e.g., Plassman et al., 2007), independence (e.g., O’Riley \& Fiske, 2012), legacy (e.g., Hunter, 2007), giving up (e.g., Hill et al., 1988) and attitudes about death and dying (e.g., Missler et al., 2011).

It was decided that the initial draft of the HILL would utilize a four-point response format (agree — somewhat agree — somewhat disagree — disagree). The four-point response format was 
selected for the target population because (1) simpler response options are less burdensome for individuals with cognitive impairment and (2) a four-point format captures greater variability compared to forced-choice, dichotomous formats. The initial version of the HILL also included both positively- and negatively-framed items, which allows the examiner to assess for biased responding. Consistent with other future-oriented self-report measures, it was decided that the HILL will not ask respondents to recall how they have been feeling over a specific time frame (e.g., one week); rather, respondents will be asked to answer based on their current attitudes toward the future. It was thought that this aspect of the HILL would also make the measure more amenable for use with individuals in later life, as those with age-related cognitive decline or cognitive impairment may have difficulty in recalling their feelings in a given time period (Bédard et al., 2003). Responses were coded as zero, one, two, or three for each item and then summed. Higher scores on the HILL indicate a greater degree of hopelessness.

Items were initially drafted by the primary author, a doctoral student in clinical psychology, based on literature review of the themes described previously, existing assessment tools, and clinical experience (as recommended by Haynes et al., 1995). Subsequently, the primary author presented the initial item pool to peers in the Mental Health and Aging Lab for feedback and revision, as well as to generate novel item ideas. The HILL was then distributed to five clinical researchers with expertise in the area of late-life depression and suicidality for further scrutiny and review. Specifically, these experts were asked to evaluate the content validity of the HILL using an assessment tool designed based on recommendations made by Haynes and colleagues (1995; Appendix B). Based on feedback from the expert panel, as well as the primary author's dissertation committee, revisions were made to the item pool of the HILL prior to its initial psychometric evaluation. 


\section{Results \& Discussion}

The pilot version of the HILL provided to expert reviewers is presented in Appendix A. Mean ratings and qualitative feedback received from the expert panel are compiled and presented in Table 1. Experts generally rated the pilot version of the HILL positively, providing evidence of content validity. Mean ratings for all items on the evaluation tool were greater than three ("neither agree nor disagree"). However, there were two items for which one reviewer responded "disagree." These included: a) "The proposed items do not conflate "hopeless situations" (e.g., terminal illness) with hopeless cognitions" and b) "The response format of the scale is acceptable for use with older adults (including individuals with mild cognitive impairment or functional limitations)." This feedback also was reflected in experts' responses to the open-ended questions on the evaluation. Specifically, expert reviewers offered differing opinions regarding the preferred response format for the HILL. One expert argued for dichotomous response format while another praised the Likert-type response format. Yet another reviewer highlighted the arguments for both response format options, but maintained a neutral position. Ultimately, the Likert-type response format was retained, as it is easier to shrink rather than to expand response options in subsequent analyses.

Another area of disagreement involved "facets" of hopelessness. Several reviewers identified potential conflation of hopelessness with other constructs (e.g., locus of control, social support, burdensomeness). Expert reviewers systematically highlighted items for potential deletion based on this issue. However, it was decided that these items would be retained for the preliminary validation study, and an empirical approach (e.g., factor analysis) would be utilized to identify items that are less related to the construct of hopelessness. There was one item that was dropped based on this feedback from reviewers: "I have a group of friends/family that will 
care about me until the end." Specifically, after further inspection, it was determined that this item was, indeed, more closely related to social support rather than hopelessness. Given that one reviewer suggested including additional content regarding social support, a new item was drafted: "I am hopeful that I will be supported socially until the end," which more directly assesses hopelessness about social support rather than social support alone.

Significant changes were made to items 12 and 24 based on expert feedback. Specifically, item 12 was split into two separate items to account for the fact that it originally assessed two different topics (legacy regarding accomplishments versus legacy involving memories). Item 24 ("When I die, I have hope that it will be relatively free of pain") was dropped because it was too closely worded to item 16 ("I have hope that my death will be relatively free of pain”).

Minor revisions also were implemented for items four, five, and nine per the suggestions of the reviewers. In item four, "excited" was changed to "positive," as one reviewer posited that "excited" is a charged term. The phrase "when my health fails" in item five was edited to instead read "if my health declines," given that one reviewer believed the former phrase was too strongly worded. For item nine, "is" was removed as an option, in order to make the item more future-oriented rather than present-oriented.

\section{Initial Validation of the HILL}

The version of the HILL that was revised based on expert feedback is included in Appendix C. This preliminary edition of the tool was included in the current, initial psychometric evaluation of the HILL. Specifically, the current study sought to assess the itemresponse characteristics and unidimensionality of the scale to inform item selection in a sample 
of older adults. Furthermore, the internal consistency and construct validity of the measure also were evaluated.

\section{Methods}

\section{Recruitment \& Procedure}

Because heterogeneous samples are preferred for the purposes of item selection, refinement, and initial psychometric analysis (Clark \& Watson, 1995), multiple recruitment methods were utilized. These included: (1) in-person recruitment of community-dwelling older adults from the greater Morgantown, WV municipal area, (2) mailed recruitment of older adults in the Mid-Atlantic region of the United States via mailing list, and (3) online recruitment of older adults via Amazon mTurk. Recruitment also was attempted in long-term care settings; however, these efforts were discontinued for several reasons. First, the recruitment process was slower than anticipated due to the low number of potential participants with decision-making capacity and without cognitive impairment. Of those who did volunteer to participate, the survey battery often proved too burdensome. Few were able to complete the survey battery in one sitting (or at all) due to fatigue and/or frailty. Finally, there were no nursing home participants who were able to complete the survey battery without assistance. Thus, the survey was read aloud and nursing home participants responded verbally. The combination of a low subsample size for long-term care and a very different administration (i.e., survey read aloud) led to the decision to exclude these participants in the current project.

In the recruitment conditions that were included, individuals were excluded if they were younger than 60 years old or were unable to complete the survey battery independently. In each condition, the demographics questionnaire and the HILL were included at the beginning of the survey battery and the order of the subsequent questionnaires was randomized. All participants 
were compensated financially for their time and effort. West Virginia University IRB approval was obtained for each recruitment method utilized in the current study. Specific details of recruitment for each method are included below.

In-Person Recruitment. Community-dwelling older adults were recruited in-person by the primary author from senior centers, churches, a senior health fair, and a family medicine clinic in the greater Morgantown, WV municipal area. Specifically, individuals who appeared to be over the age of 60 were approached and their interest in participating in the current study was assessed. If the individual expressed interest, their age was obtained. The survey was not administered to those who were not at least 60 years old. Individuals meeting the age criteria were provided with five dollars, a cover letter consent form, a survey packet, a list of local and national mental health resources, and a pre-stamped envelope in which to return the survey. Several participants opted to complete the survey on-site $(n=11)$, but most elected to take it home and return the survey via mail. Response rate was strong, as 79 surveys were administered and 67 usable surveys were returned (84.8\%). One blank survey and one partially completed survey (only demographics section) were returned with the five dollars included in each.

Mailed Recruitment. In prior mailed surveys conducted in the Mental Health and Aging Lab and the Older Adult Anxiety Lab, participants were asked about their willingness to participate in future studies. A list of these individuals who agreed to be contacted for future studies was utilized in the current study. An invitation to participate in the current study was mailed to 90 individuals. An invitation was not sent to individuals on the list who previously had been recruited from any of the sites utilized in the in-person recruitment method. Furthermore, men were specifically targeted, given that a higher number of women participants was anticipated in the in-person and online recruitment conditions. Thirty-nine (43.3\%) individuals 
mailed back the invitation and indicated interest. These potential participants were provided with five dollars, a cover letter consent form, a survey packet, a list of local and national mental health resources, and a pre-stamped envelope in which to return the survey. Of the 39 surveys mailed to these individuals, $32(82.1 \%)$ completed surveys were returned. No blank surveys or incomplete surveys were returned via this recruitment method.

Online Recruitment. Online older adult participants were recruited via Amazon mTurk. These participants represented all regions of the United States. Special steps were taken to ensure that online participants were above the age cutoff. First, the study advertisement clearly stated that only individuals ages 60 and over were eligible for participation. Next, participants were asked to supply their birth-year on the first page of the survey. Despite the clearly-worded advertisement for older adults, a large number of individuals younger than the age cutoff attempted to participate in the survey and were not allowed to continue based on the birth-year supplied ( $\mathrm{n}=704)$. As an additional validity check, participants were asked to provide their age at the conclusion of the survey, in case a younger individual invented a birth-year for financial compensation. If a participant's self-reported age and birth-year did not correspond (within two years), that participant also was dropped from analyses $(n=24)$. Finally, an additional 25 online participants were not included, as they did not complete the survey or spent fewer than 15 minutes completing the measures. Thus, 919 individuals initiated or attempted the online survey and $166(18.1 \%)$ were retained for the present analyses. Online participants were financially compensated using rates pre-determined by Amazon mTurk based on the number of questions in the survey battery. In addition, all participants were provided with a list of national mental health resources available.

\section{Participants}


The total sample for the current study included 265 adults over the age of 60 . The mean age was 71.1 ( $\mathrm{SD}=6.7)$ with ages ranging from 60 to 99 . One-hundred sixty-two $(61.1 \%)$ were women and $103(38.9 \%)$ were men. The vast majority of the sample identified as Caucasian $(233 ; 88.6 \%)$. The total sample also included individuals who identified as African American $(16 ; 6.1 \%)$, Hispanic $(4 ; 1.5 \%)$, American Indian $(3 ; 1.1 \%)$, Asian/Pacific Islander $(3 ; 1.1 \%)$, and other or mixed race $(6 ; 2.3 \%)$. Regarding marital status, the majority of the sample reported being married or having a live-in partner $(130 ; 49.1 \%)$. Thirty-five reported being single (13.2\%), 39 indicated being separated or divorced (14.7\%), and 61 reported being widowed $(23.0 \%)$. The sample was diverse in terms of education. A slight majority had a college degree (99; 37.4\%). Twenty individuals had less than a high school education (7.6\%), seven had a GED (2.6\%), 65 graduated high school $(24.5 \%)$, and 55 reported attending some college, but not graduating (20.6\%). Nineteen participants had advanced graduate degrees (7.2\%). The sample also was diverse in terms of rurality. Thirty-five (13.2\%) individuals reported a rural hometown ( $<2,500$ residents), $64(24.2 \%)$ indicated being from a small town (more than 2,500 but less than 20,000), 95 (35.9\%) reported residing in a small city (more than 20,000 but less than 100,000), and $71(26.8 \%)$ identified their hometown as a large city (more than 100,000 residents).

There were several demographic differences within the larger sample with regard to recruitment method. Males were significantly more represented in the mailed recruitment condition, which is not surprising, given that males were over-sampled in the mailing to compensate for over-representation of females among the in-person and online recruitment conditions. Participants recruited online were significantly younger on average (M=69.4, $\mathrm{SD}=4.9)$ compared to the in-person $(\mathrm{M}=74.6, \mathrm{SD}=8.4)$ or mailed ( $\mathrm{M}=72.3, \mathrm{SD}=8.4)$ conditions. There also were significant differences with regard to education. In the mailed condition, there 
were more individuals with a college degree compared to those without $(65.6 \%$ and $34.4 \%$, respectively). The opposite was true in the in-person sub-sample (16.4\% and 83.6\%, respectively). Finally, there was an even distribution in terms of college degree versus no college degree within the online recruitment condition (51.8\% and 48.2\%, respectively). With regard to marital status, significantly more participants reported "single" status and fewer participants reported "married" status in the online condition compared to the in-person and mailed recruitment conditions. Online participants also were more likely to describe their hometown as a "large city." There were no significant differences across recruitment subsamples in terms of race/ethnicity.

\section{Measures}

In addition to the HILL, measures of varying degrees of hypothesized relatedness to hopelessness were included in the current study to evaluate construct validity. Assessment measures that had previously demonstrated evidence of reliability and validity among older adult samples were utilized whenever possible. The full battery of measures was piloted with members of the Mental Health and Aging Lab for proofing. The average length of time taken to complete the battery was approximately 25 minutes.

Beck Hopelessness Scale (BHS; Appendix D). The BHS is a 20-item self-report measure of hopelessness that utilizes a true/false response format (Beck et al., 1974). In the hopelessness literature, the BHS has accumulated the greatest amount of empirical support and is the most commonly-used assessment tool across age groups. The BHS has been examined in psychiatric inpatient samples (e.g., Durham, 1982), community-dwelling adults (e.g., Neufeld \& O’Rourke, 2009), long-term care settings (e.g., Ron, 2004), college students (e.g., Steed, 2001), and depressed outpatients (e.g., Hill et al., 1988). Reliability coefficients (Cronbach's $\alpha$ ) 
reported for the BHS have generally ranged between 0.82 and 0.93 (Steed, 2001), suggesting good internal consistency. Among older adult samples, the BHS has demonstrated construct validity through associations with measures of depression (Beck Depression Inventory; r=.41, $\mathrm{p}<.001$; Hill et al., 1988), self-rated health ( $\mathrm{r}=.25, \mathrm{p}<.01$; Hill et al., 1988), and suicidal ideation (Geriatric Suicidal Ideation Scale; r=.77, $\mathrm{p}<.01$; Neufeld \& O’Rourke, 2009). The BHS was not significantly correlated with age in these studies (Hill et al., 1988; Neufeld \& O'Rourke, 2009). As the BHS is the putative "gold standard" measure of hopelessness, it is included in the current study in order to evaluate the criterion-related validity of the HILL. It was expected that the magnitude of the correlation coefficient between the BHS and the HILL would be strong, but would not represent complete overlap.

Geriatric Depression Scale- Short Form (GDS-SF; Appendix E). The Geriatric Depression Scale (GDS) is a 30-item yes/no measure of depressive symptoms designed for use with older adults (Yesavage et al., 1983). Specifically, the GDS does not assess for somatic symptoms of depression, given the high degree of overlap between depressive symptoms and health problems among older adults (Yeasavage et al., 1983). In addition, the "yes" versus "no" format is believed to increase the utility of the instrument among individuals with mild to moderate dementia (Sheikh \& Yesavage, 1986). Sheikh and Yesavage (1986) developed a shortened 15-item version of the GDS that was utilized in the present study. A cut-off score of 5 on the GDS-SF has been proposed for the detection of major depression. The sensitivity and specificity of this cut score for detecting major depression has been evaluated in a variety of populations, including community-dwelling and treatment-seeking older adults (92\% sensitivity, 89\% specificity; Sheikh \& Yesavage, 1986), home health care patients (72\% sensitivity, 78\% specificity; Marc, Raue, \& Bruce, 2008), and primary care outpatients (91\% sensitivity, 72\% 
specificity; D’Ath, Katona, Mullan, Evans, \& Katona, 1994). Construct validity of the GDS-SF has been established via strong correlations with other measures of depression (e.g., Herrmann et al., 1996) and weak-to-moderate correlations with measures of self-rated health and somatic complaints (e.g., Boey, 2000). Studies have routinely reported adequate internal consistency for the GDS-SF (e.g., Marc et al., 2008; Friedman, Heisel, \& Delavan, 2005). With regard to hopelessness, the GDS has demonstrated strong correlations with the Geriatric Hopelessness Scale in a nursing home sample (r=.67; Meeks \& Tennyson, 2003), a psychiatric inpatient sample (r=.66; Trenteseau et al., 1989), and a combined nursing home/psychiatric inpatient sample (r=.61; Uncapher, et al., 1998). Thus, it was hypothesized that the magnitude of the correlation between the GDS-SF and the HILL in the current study would be strong. As in prior studies examining the relation between hopelessness measures and the GDS-SF (e.g., Meeks \& Tennyson, 2003), the GDS hopelessness item (e.g., "Do you feel that your situation is hopeless?") was excluded from the current analyses.

Suicide Behaviors Questionnaire-Revised (SBQR; Appendix F). The SBQR is a fouritem measure of suicide risk that assesses lifetime suicidal behavior (e.g., plans, attempts), suicidal ideation within the past year, lifetime disclosure of suicidal intent, and current estimation of a future attempt (Cole, 1988). Total scores range from 3 to 18 with higher scores indicating greater risk for suicide. The SBQR has been validated in both clinical and nonclinical samples, and a cut-off score of seven has demonstrated high sensitivity (93\%) and specificity (95\%) for differentiating between suicidal and non-suicidal individuals in the general adult population (Osman et al., 2001). Among older adults, the SBQR has demonstrated adequate internal consistency $(\alpha=0.70)$ and a moderate correlation with a measure of depressive symptoms (r=.42; Bamonti, Price, \& Fiske, 2013). The association between the SBQR and 
hopelessness in later life has not been examined; however, given the moderate correlation between the SBQR and a measure of depression, a moderate correlation was hypothesized in the current study. In addition to overall suicide risk, the SBQR was selected for the current study because the fourth item asks for the participant's current estimation of future risk ("How likely is it that you will attempt suicide someday?"). Thus, this item utilizes the same time-frame as the HILL and the BHS. Moreover, individuals' own estimation of future risk has been shown to differentiate between suicidal versus non-suicidal inpatients (Conrad et al., 2009). A moderate correlation between SBQR-Item 4 and the HILL also was anticipated.

Duke Social Support Index (DSSI; Appendix G). The DSSI is a 35-item instrument designed to measure perceived social support (Landerman, George, Campbell, \& Blazer, 1989). An abbreviated 11-item version of the measure has demonstrated good psychometric properties in samples of older adult women (Powers, Goodger, \& Byles, 2004) and chronically-ill older adults (Koenig et al.,1993). The abbreviated DSSI contains two subscales, including satisfaction with support ( 7 items) and social interaction (4 items). In the current study, only the satisfaction with support scale was used. This subscale asks participants to select whether they are 1 (hardly ever), 2 (some of the time), or 3 (most of the time) satisfied with their current level of social support. Higher scores indicate greater satisfaction with support. In a prior study conducted with older adults, one item was dropped from the satisfaction subscale based on factor analysis (e.g., "How satisfied are you with the kinds of relationships you have with your family and friends?"; Powers et al., 2004). Only the six items that exhibited unidimensionality were utilized in the present study. Internal consistency of the satisfaction with the six-item support subscale has been found to be good $(\alpha=.80$; Powers et al., 2004). Furthermore, the construct validity of the satisfaction with support subscale has been demonstrated with positive and small-to-moderate 
correlations with perceived health, as well as a negative and moderate correlation with overall stress (Powers et al., 2004). Though the relation between the DSSI and a measure of hopelessness has not been previously evaluated, a strong, inverse relation between the DSSI and the HILL was hypothesized, given the previously documented strong relation between the BHS and other interpersonal variables (e.g., loneliness; $r=0.66$; Cukrowicz et al., 2011).

Geriatric Anxiety Inventory- Short Form (GAI-SF; Appendix H). The Geriatric Anxiety Inventory (GAI) is a 20-item agree/disagree screening tool for anxiety and worry. Utilizing corrected item-total correlations, item response rates, and receiver operating characteristic (ROC) analyses, Byrne and Pachana (2011) derived a five-item shortened version of the GAI. They found a high correlation between the GAI-SF and the original GAI ( $\mathrm{r}=.88)$, as well as the state subscale of the State-Trait Anxiety Inventory (STAI; Spielberger, Gorsuch, \& Lushene, 1970; r=.47). Additional evidence for construct validity was demonstrated through weak-to-moderate correlations between the GAI-SF and the GDS ( $\mathrm{r}=.37$ ), the Mini-Mental State Examination (MMSE; Folstein, Folstein, \& McHugh, 1975; r=-.04), education level (r=.08), and age ( $r=-.05)$. The GAI-SF has been established among community-dwelling older women $(\alpha=.81$; Byrne $\&$ Pachana, 2011), as well as long-term care residents $(\alpha=.73$; Gerolimatos, Gregg, \& Edelstein, 2013). Few studies have investigated the relation between anxiety symptoms and hopelessness and none has evaluated their relation among older adults. CochraneBrink and colleagues (2000) found a strong correlation between the Beck Anxiety Inventory (BAI; Beck \& Steer, 1990) and the BHS (r=.50) among psychiatric patients; however, this relation was not as strong as the relation between the Beck Depression Inventory (BDI) and the BHS ( $r=.63)$. Based on these findings, it was hypothesized that the magnitude of the relation 
between the GAI-SF and the HILL would be medium-to-strong in the current study, though not as strong as the relation between the HILL and the GDS-SF.

\section{Interpersonal Needs Questionnaire- Perceived Burdensomeness Subscale (INQ-PB;}

Appendix I). The INQ-PB is a six-item measure designed to assess the degree to which a person feels that s/he is a burden on people in their lives (Van Orden, Witte, Gordon, Bender, \& Joiner, 2008). This measure utilizes a seven-point Likert-type format. The participant is asked to rate the degree to which they agree or disagree with statements related to perceived burdensomeness (e.g., "These days I feel like a burden on the people in my life."). In a sample of communitydwelling older adults, the INQ-PB has demonstrated adequate internal consistency $(\alpha=.90)$ and construct validity via strong correlations with depression and geriatric suicidal ideation (Cukrowicz et al., 2011). In this same study, the INQ-PB also demonstrated a strong correlation with the BHS $(r=0.54)$; thus, a strong correlation between the HILL and the INQ-PB was expected in the present study.

Self-Rated Health. The following item was utilized as a global indicator of physical health: "How would you rate your health at the present time: Excellent, good, fair, or poor?" Despite its simplicity, a plethora of studies with older adults have found a strong relation between self-rated health and various objective indicators of health status (e.g., Christian et al., 2011; Lima-Costa, Cesar, Chor, \& Proietti, 2012). Moreover, a systematic review of 27 studies found that global self-rated health is a strong, independent predictor of mortality, even after controlling for specific health status indicators and known mortality predictors (Idler \& Benyami, 1997). Among older adults, a moderate correlation between self-rated health and the BHS has been reported ( $\mathrm{r}=.25$; Hill et al., 1988). It was expected that the magnitude of the correlation between self-rated health and the HILL would be moderate. Furthermore, because 
the HILL is designed to reduce bias against physically ill older adults, it was hypothesized that the correlation between the HILL and self-rated health would be smaller compared to the relation between self-rated health and the BHS.

Marlowe-Crowne Social Desirability Scale- Revised (SDS-R; Appendix J). The Marlowe-Crowne Social Desirability Scale (SDS) is a 33-item true/false measure designed to detect socially desirable responding in self-reports (Crowne \& Marlowe, 1960). Evidence has demonstrated that, compared to individuals with lower scores on the SDS, those with higher scores are more likely to inhibit aggression, respond to social reinforcement, show preference for low-risk behavior, and avoid social evaluation (Paulhus, 1991). The SDS has demonstrated adequate internal consistency ( $\alpha^{\prime} \mathrm{s}=.73-.88$; Paulhus, 1991), as well as test-retest reliability over one-month (r=.88; Crowne \& Marlowe, 1964) and one-week ( $r=.84$; Fisher, 1967) intervals. Over the years, several short forms of the SDS have been developed due to the sheer length of the measure (e.g., Reynolds, 1982; Strahan \& Gerbasi, 1972). Fischer and Fick (1993) systematically evaluated the various short-forms against the original SDS and proposed revised short-forms using structural equation modeling and modification indices. Fischer and Fick advocated for the use of a six-item version (SDS-R), which was utilized in the current study. Sample items include: "I have never intensely disliked someone" and "I am sometimes irritated by people who ask favors of me" (reverse-scored). The SDS-R demonstrated good model fit (GFI=.996) and internal consistency $(\alpha=.76)$ in a study of 390 undergraduate students (Fischer \& Fick, 1993). With regard to older adults, the SDS has exhibited adequate internal consistency ( $\alpha$ $=0.82)$ and construct validity through moderate correlations with measures of depression ( $\mathrm{r}=-$ $0.33)$ and anxiety ( $r=-0.28$; Thomsen et al., 2005). 
Mixed results have been reported regarding the relation between hopelessness and social desirability. Linehan and Nielson (1981) examined the relations between the BHS, the Edwards Social Desirability Scale (ESDS; Edwards, 1957), and the Suicidal Behaviors Questionnaire (SBQ; Linehan and Nielson, 1981) among 196 Seattle area shoppers. They found that the relation between the BHS and the SBQ became insignificant after controlling for scores on the ESDS, leading the authors to question the clinical utility of hopelessness measures. However, it has been noted that the items on the ESDS are largely pathological in content (Paulhus, 1991) and the Linehan study did not utilize a clinical population. A subsequent study among 130 inmates found that the relations between the BHS and two measures of suicidal behavior remained significant after controlling for scores on the ESDS (Ivanoff \& Jang, 1993). Likewise, Petrie and Chamberlain (1983) found that scores on the Marlowe-Crowne SDS did not mediate the relation between hopelessness and suicidal behaviors among suicide attempters, despite a moderate correlation between the BHS and SDS ( $r=-.30)$. Based on this research, it was hypothesized that the SDS-R would be moderately (and inversely) correlated with the HILL. Furthermore, it was hypothesized that the relation between the HILL and the SBQR will remain significant after controlling for the SDS-R.

Other Health-Related Measures. In addition to the self-rated health item, several other indicators of health status were included in the current study. These included two items related to pain. One item focused on frequency of pain (e.g., "How much bodily pain have you had in the past 4 weeks?”) and one item focused on daily interference due to pain symptoms (i.e., "During the past 4 weeks, how much did pain interfere with your normal work (including both work outside the home and housework)?"). A Likert-type response format was used for each of these questions (1-6 and 1-5 respectively). Furthermore, a yes/no checklist including ten of the 
most commonly-experienced health conditions was utilized (Appendix K). These conditions included arthritis, heart trouble, depression, high blood pressure, diabetes, anxiety, cancer, obesity, breathing problems, and back problems. "Yes" was coded as " 1 " and these were totaled to provide an overall indication of health status.

\section{Analyses}

All analyses were conducted using SAS 9.4. Following data cleaning procedures, the data were first analyzed for patterns of missingness. In general, there were few instances of missing data in the current project. Individuals in the online recruitment condition were less likely to have missing data, overall. This is probably due, at least in part, to the fact that individuals were prompted to respond if an item was left blank before moving on to the next page. This likely resulted in fewer accidental cases of missingness. There was slightly more missing data on the BHS and the HILL (6.0\% and 5.3\%, respectively) compared to other measures (e.g., GDS = 2.3\%). There were no discernable patterns of missingness within these measures in terms of individual items being left blank more consistently. For example, reversescored items were no more likely to be left blank compared to standard items. It is possible that the lengthier and more complex nature (e.g., alternating between standard and reverse-coded items) of the items on the HILL and BHS led to higher rates of missing data.

Tabachnick and Fidell (2007) suggest that, if roughly 5\% or less of data are missing at random from a large dataset, virtually any procedure for handling miss data will yield similar results. The data was subjected to Little's Missing Completely at Random (MCAR) Test in order to examine patterns of missingness. Using this test, a non-significant chi-square is indicative of data that are missing completely at random. The test revealed that the data were, 
indeed, missing completely at random $\left(\chi^{2}=3659.28(\mathrm{df}=3586), \mathrm{p}=0.19\right)$. Thus, Estimation Maximization (single imputation) was selected for use in the current project.

\section{Results}

Before testing study hypotheses, analyses were conducted to evaluate the appropriateness of combining the three subsamples into a single sample. Results revealed that, in addition to the demographic differences across subsamples outlined in the Methods section, there were mean differences in key study variables between the three subsamples. Overall, mean scale scores represented greater psychopathology among online participants compared to in-person or mailed participants. For example, the mean total score on the HILL was $12.14(\mathrm{SD}=9.55)$ among mailed participants, $15.23(\mathrm{SD}=14.06)$ among in-person participants, and $29.21(\mathrm{SD}=19.05)$ among online participants. Likewise, the mean total score on the GDS was 1.97 (SD=2.47), 2.34 $(\mathrm{SD}=2.79)$, and $5.38(\mathrm{SD}=4.14)$, respectively. Given the demographic differences across subsamples, these mean differences in study variables were expected. For instance, the online sample includes more younger-old adults, and rates of psychopathology are negatively associated with age (e.g., Gum, King-Kallimanis, \& Kahn, 2009). Even so, the nature of the correlation matrix was largely the same across subsamples. The direction of correlation coefficients was identical between subsamples and the magnitude of the correlations was generally the same. For example, using Fisher's $r$ to $\mathrm{z}$ transformation, which accounts for sample size, there was no significant difference in the relation between the HILL and the BHS across the in-person ( $r=.67)$, mailed $(r=.60)$, or online $(r=.79)$ recruitment methods. Likewise, there was no significant difference in the relation between the HILL and the SBQ-R across the in-person ( $\mathrm{r}=.27)$, mailed $(\mathrm{r}=.24)$, and online $(\mathrm{r}=.48)$ subsamples. This same pattern was true for the correlations between most primary study variables. The consistency in intercorrelations between primary study 
variables across recruitment methods provided additional support for combining these subsamples into a larger sample for the remainder of the analyses.

\section{Item Selection}

As outlined by Clark and Watson (1995), multiple analytic strategies were utilized to select items for the final version of the HILL.

First, item-response characteristics were examined. Items that capture greater variability are preferred over those that have highly skewed distributions, as items with diminished variability do not provide valuable information about the construct (Clark \& Watson, 1995). Thus, items were examined for highly unbalanced distributions (e.g., 95\% endorse "agree" or "somewhat agree"). There were no items where $95 \%$ selected an agreeing response or $95 \%$ selected a disagreeing response. However, $92.5 \%$ selected "agree" or "somewhat agree" on item 16 ("I have hope that my death will be relatively free of pain"). This item was identified as a candidate for deletion.

Next, items were further examined for unidimensionality. Clark and Watson (1995) suggested that the vast majority of individual inter-item correlation values should fall between 0.15 and 0.50 . Inter-item correlations below 0.15 may be indicative of disparate constructs (multidimensionality), whereas correlations greater than 0.50 may represent redundancy. Unfortunately, as noted by Clark and Watson, examining individual item-item correlations can be unwieldy and impractical. For example, an item pool of 30 items results in 435 individual intercorrelations to examine. Clark and Watson suggest using an exploratory factor analysis as a more practical alternative.

A principal components analysis was conducted (recommended by Cortina, 1993) using all 30 items from the HILL. For the purposes of item selection, rotation is considered irrelevant 
and unnecessary. In order to determine the number of components to specify, Eigenvalue $>1$ was used as a cutoff. Using this criterion, a four-component structure was specified (see Table 2 for factor loadings). Clark and Watson (1995) noted that items with stronger loadings on the first principal component and weaker loadings on subsequent components are ideal, as the first principal component explains the greatest amount of variance in the construct. Thus, items that loaded weakly on the first unrotated factor $(<.40)$ and/or items that load strongly onto subsequent factors $(\geq .40)$ were considered as candidates for removal from the HILL. Only item 16 loaded weakly on the first factor. However, several items loaded strongly onto subsequent factors. Items loading strongly onto the second component were 4, 6, 8, 16, and 20. Notably, these were all positively-framed items (i.e., "hopeful"). Items 16 and 20 also loaded significantly onto the third component. The fourth component was comprised of items 12,24 , and 28 , which are all items related to "legacy." Each of these items also was considered as a candidate for deletion.

With these items potentially removed, item-item correlations were then examined among the remaining items for items that may be redundant (e.g., $r>0.50$ ). Many of the item-item correlation coefficients were above this criterion. In order to select items to retain versus delete, factor loadings were re-examined. HILL item 17 ("My current situation is hopeless") was found to have the strongest loading on the first principal component (e.g., "hopelessness"). Any item that was correlated with this item at a level of $r>.60$ was identified for deletion to reduce redundancy. Specifically, items 3, 13, 14, 15, 18, 19, 25, and 30 were deleted. Following deletion of these items, only one item-item correlation remained at the level of $r>.60$ (item 1 and item $2, \mathrm{r}=.67)$. Item 2 was deleted, as item 1 loaded more strongly on the first principal component compared to item 2. At this point, item trimming was ceased. Thirteen items remained on the HILL and all item-item correlations were greater than 0.20 and less than 0.60 . 
Furthermore, the content of the remaining items appeared to assess general hopelessness, as well as hopelessness about a range of issues of relevance to later life (e.g., declining health, independence, pain, the dying process, burdensomeness).

Following these analyses, items 1, 5, 7, 9, 10, 11, 17, 21, 22, 23, 26, 27, and 29 remained on the shortened version of the measure (HILL-Shortened or "HILL-S"). This revised version of the scale is presented in Appendix L. In the remainder of the study, results were reported for two versions of the scale: (1) the full version of the HILL with the exception of item 16, which was the only proposed item that did not load onto the first principal component (referred to as the HILL), and (2) the shortened-version specified by empirically-driven item selection (referred to as the HILL-S).

\section{Reliability}

With regard to internal consistency, Clark and Watson (1995) posited that the average inter-item correlation should fall between 0.15 and 0.50 . The average inter-item correlation was 0.43 for the HILL and 0.42 for the HILL-S. Cronbach's alpha, another index of internal consistency, also was calculated for both scales. Cronbach's alpha for the HILL was 0.96. Cronbach's alpha for the HILL-S was 0.89. Test-retest reliability was not evaluated in the current study.

\section{Construct Validity}

The construct validity of the HILL was tested via a Pearson's product moment correlation matrix including measures of hypothetically varying degrees of relatedness. Descriptive statistics for all study measures, including the HILL and HILL-S, are reported in Table 3. Bivariate correlations are reported in Table 4. 
Using Fisher's r-to-z transformations, the magnitudes of the correlation coefficients for the HILL and the HILL-S were compared. There were no significant differences between the two versions of the measure, except with regard to the INQ-PB. The correlation between the HILL and the INQ-PB ( $r=0.82)$ was significantly stronger than the correlation between the HILL-S and the INQ-PB $(r=0.76 ; z=2.1, p<0.05)$. In addition, the correlation coefficients of the BHS were compared to those of the HILL and the HILL-S. Correlation coefficients of the BHS were not significantly different from those of either the HILL or the HILL-S, except for the relations with the INQ-PB. Specifically, the relation between the BHS and the INQ-PB ( $r=0.66)$ was significantly lower than either the HILL ( $\mathrm{r}=0.82$ ) or the HILL-S ( $\mathrm{r}=0.76)$. Regarding correlations with suicide risk, the INQ-PB, GDS, BHS, HILL, and HILL-S were all equivalently related to the $\mathrm{SBQR}$, as well as item four of the $\mathrm{SBQR}$.

Overall, the HILL and the HILL-S were strongly associated with measures of hopelessness, geriatric depression, perceived burdensomeness, and social support. Medium relations were found with suicide risk, anxiety, self-rated health, physical health, and pain interference. The HILL and the HILL-S demonstrated small associations with social desirability and pain frequency. Finally, there was no relation observed between age and either the HILL or the HILL-S.

Contrary to expectation, there was no difference in the relations between health variables (e.g., self-rated health, physical health, pain frequency, pain interference) and the HILL or HILL$\mathrm{S}$ versus their relation to the BHS. The relation between the HILL and the SBQR remained significant after controlling for social desirability $(\mathrm{B}=0.07, \mathrm{SE}=0.01, \mathrm{p}<.001)$, as hypothesized. The same was observed for the HILL-S $(\mathrm{B}=0.15, \mathrm{SE}=0.02, \mathrm{p}<.001)$.

\section{Exploratory Analyses}


Given the lack of clarity regarding the role of hopelessness in the relation between depressive symptoms and suicidality, mediation and moderation models were examined separately using the HILL, HILL-S, and BHS.

With regard to moderation models, separate linear regression models were used to examine the interaction effects of the HILL, HILL-S, and BHS on the relation between the GDS and the SBQR. All variables were centered prior to running the analyses to reduce potential multicolinearity. The final models for the HILL, HILL-S, and BHS are included in Tables 5, 6, and 7, respectively. There was a significant interaction effect observed between the HILL and the GDS in relation to suicide risk as measured by the SBQR (Table 5). Follow-up analyses conducted using a median split revealed that the relation between depressive symptoms and suicide risk was not significant in the context of lower hopelessness as measured by the HILL ( $\mathrm{B}=0.13$ ( $\mathrm{SE}=0.08), \mathrm{p}=.12$ ). The same relation was strong in the context of higher hopelessness as measured by the HILL $(\mathrm{B}=0.38(\mathrm{SE}=0.07), \mathrm{p}<.001)$. This same interaction effect was exhibited between the HILL-S and the GDS in relation to the SBQR (Table 6). The interaction between the BHS and the GDS in relation to the SBQR was not significant (Table 7). Simple slopes analyses were conducted for each of the three moderation models and graphs are presented in Figures 1, 2, and 3, respectively.

The bootstrapping method was used to test mediation. A SAS macro was employed designed by Preacher and Hayes (2008) to conduct these analyses. Bootstrapping is a method of estimating the indirect effects of mediator variable(s) on the relation between the independent variable and dependent variable. A score of zero indicates no effect. Therefore, the mediation effect is considered significant if the $95 \%$ confidence interval does not include zero. Biascorrected and accelerated bootstrap confidence intervals resampled 5,000 times were utilized. 
The unstandardized coefficient of the indirect effect of the HILL on the relation between the GDS and the SBQR was 0.05 (bias-corrected 95\% CI: 0.01-0.10), suggesting a significant mediation effect. Likewise, the unstandardized coefficient for the HILL-S on the same relation was 0.13 (bias-corrected 95\% CI: 0.03-0.24). There was not a significant mediation effect for the BHS on the relation between the GDS and SBQR (coefficient=0.04, 95\% CI $=-0.08-0.15$ ).

Sobel Tests were used to further confirm findings from these mediational analyses. Specifically, the HILL and the HILL-S each mediated the relation between GDS and the SBQR (Sobel Test $=2.45, \mathrm{p}<.05$ and Sobel Test $=2.55, \mathrm{p}<.05$, respectively), while the BHS did not significantly mediate the same relation (Sobel Test $=0.68, \mathrm{p}=0.49$ ).

\section{Discussion}

The current project sought to develop a new scale to assess hopelessness among older adults and individuals with life-limiting illness. Specifically, hopelessness is a prominent risk factor for suicide; however, current assessment instruments have significant limitations for use with individuals in later life. For instance, the BHS lacks item content that is tailored to older individuals and may contain items that are biased against older adults (e.g., "I cannot imagine what my life will be like in 10 years"). Furthermore, the GHS is comprised of items that lack face validity, may be too culturally specific, and have demonstrated poor psychometric properties. To address these current limitations, items for the new scale were generated and reviewed by multiple sources, including members of a research laboratory focused on mental health and aging, as well as experts in the field of geriatric depression and suicide. Experts in geropsychology rated the proposed tool positively, providing evidence of content validity. A pool of 30 items was then subjected to psychometric analysis, including item selection and an initial examination of reliability and validity. Two viable versions of the scale, the Hopelessness 
Inventory for Later Life (HILL) and the HILL-Shortened (HILL-S), exhibited strong itemresponse characteristics, as well as preliminary evidence of unidimensionality, internal consistency, and construct validity.

Within the current sample, the Likert-type response option presented in the HILL appeared acceptable to participants. For example, there were low rates of missing data in all recruitment conditions, including paper/pencil survey and online survey formats. In the data cleaning process, there were no participants who simply checked all of the boxes down the rightmost or left-most columns. This suggests that participants were attentive to the inclusion of reverse-coded items. It is important to note, however, that the current study included only individuals with at least enough cognitive capacity to complete the survey battery without formal assistance. It is possible that the Likert-type response format of the HILL may have less utility among individuals with cognitive impairment; however, this represents an area for future investigation.

With regard to the principal components analysis employed for item selection, only one item (16: "I have hope that my death will be relatively free of pain") did not load on the first principal component, labeled "hopelessness." In addition to potentially loading onto other constructs, item 16 also exhibited a skewed distribution. The vast majority of older adults (greater than 90\%) endorsed hope about a death that is free of pain. These two aspects suggested that this item does not provide valuable information about hopelessness. Thus, it was excluded from any version of the HILL.

Otherwise, all HILL items exhibited adequate variability and appear to measure the same construct, evidenced by loading onto the first principal component. A few items appear to tap additional constructs. For instance, items 4, 6, 8, and 20 loaded significantly onto the second 
principal component. An examination of these items' content suggests a common theme of "hope" or "optimism," as all were positively framed items (e.g., "Even though I've lived most of my life, I still have reasons to be positive about the future"). The behavior of these items in factor analysis raises the question of whether "hope" and "hopelessness" represent opposite ends of the same continuum or are separate constructs entirely. The fact that some items load onto only the "hopelessness" factor, others onto both the "hopelessness" and "hope" factors, and at least one onto only the "hope" factor, lends more support to the existence of separate, yet overlapping constructs. The few studies in the current literature that have examined both "hope" and "hopelessness" also support this notion. For example, Benzein and Berg (2005) found a strong, but not overlapping, inverse correlation $(\mathrm{r}=-0.58)$ between measures of hope (e.g., Hearth Hope Index) and hopelessness (e.g., Beck Hopelessness Scale) among palliative care patients. Nonetheless, there could be benefits to an assessment measure that assesses both hope and hopelessness, given that both provide valuable information regarding beliefs about the future. Thus, these "hope" items are retained on the full version of the HILL, given that they also loaded onto the first principal component and, hence, still provide information about hopelessness. They are excluded from the abbreviated version of the scale, which includes a more unidimensional assessment of the construct with less redundancy among items. The nature of the relationship between "hope" and "hopelessness" in later life represents a potential topic of future study, perhaps by including the HILL and a measure of "hope" or "optimism" (e.g., Adult Hope Scale; Snyder et al., 1991) and examining their relationship.

Several HILL items also loaded onto a third construct of "legacy" (i.e., items 12, 24, and 28). Like hopelessness, legacy is a future-oriented construct. In the design phase, items were carefully worded to focus on hopelessness about legacy (e.g., "I feel hopeful about the legacy I 
left behind"). However, upon further inspection, two of the items appear less clear (e.g., "No one will remember me after I'm gone"). Nonetheless, these items also loaded significantly onto the primary construct, and are thus retained on the full version. As with the "hope" items, the "legacy" items are excluded from the HILL-S in order to provide a more unidimensional assessment of the construct.

Among the remaining items, many were strongly correlated with one another. A few were correlated at a level of $r>0.60$. For example, item 17 ("My current situation is hopeless") was found to overlap strongly with several other items (e.g., item 15: "There is nothing left to look forward to in my life"). Redundancy was reduced on the HILL-S by evaluating items with high inter-item correlations and eliminating those that were less related to the primary construct (i.e., determined by examining loadings on the first principal component). All items were retained on the full HILL in order to optimize the range of hopelessness content assessed by the scale.

Both the HILL and the HILL-S show preliminary evidence of reliability and validity in the current study. Specifically, internal consistency reliability is strong, indicated by mean interitem correlations (between 0.15 and 0.50 ) and high Cronbach's alpha. Test-retest validity was not examined in the current study and is certainly a direction for further research with these instruments.

Results are quite promising regarding the construct validity of both the HILL and HILLS. Relations with other measures included in the study were all in the expected direction and of the expected magnitude. For instance, as predicted, a strong correlation was observed between the HILL and a measure of geriatric anxiety $(\mathrm{r}=0.49)$, but not as strong as the HILL's correlation with a measure of geriatric depression $(\mathrm{r}=0.82)$. Additionally, the relation between the 
HILL/HILL-S and BHS was strong and, with the exception of perceived burdensomeness, there were no differences between the HILL/HILL-S and BHS in terms of their relations with other constructs, including suicide risk, geriatric depression, social support, anxiety, etc. Because the BHS is considered the putative "gold standard" in the assessment of hopelessness, these findings suggest that both versions of the HILL capture hopelessness, while still including content that is specifically relevant to older adults (which the BHS lacks).

Moreover, both mediational and moderational models were supported for the HILL and HILL-S regarding the relation between geriatric depression and suicidality. The BHS did not function as a mediator or a moderator in the same relation. From a theoretical perspective, hopelessness should function as a mediator (e.g., Beck et al., 1975) or moderator (e.g., Van Orden, 2010) in the relation between depression and suicidality. Thus, the current study lends greater support to the HILL and HILL-S in the assessment of late-life hopelessness compared to the BHS. Perhaps the inclusion of more targeted facets of geriatric hopelessness on the HILL (e.g., hopelessness specifically about social support, independence, the dying process, etc.) accentuates depressive content that is more closely related to late-life suicidality compared to the BHS, which is a more general measure of hopelessness or pessimism.

Another promising finding of the current study centers on the relations between the HILL and the HILL-S and health-related measures such as pain, self-rated health, and the health conditions checklist. Notably, each of the correlations were in the small-to-moderate range, suggesting that neither version of the HILL is highly conflated with poor health. This suggests that there may have been respondents with realistically hopeless prognoses in terms of physical health (e.g., cancer, renal failure, COPD) that endorsed lower levels of hopelessness. This 
finding indicates that the HILL separates situation from outlook, which was a primary purpose in proposing these new scales of geriatric hopelessness.

With regard to perceived burdensomeness, the INQ-PB's stronger relation to the HILL versus the BHS is not surprising, given that the HILL includes item content that specifically addresses hopelessness about interpersonal variables (e.g., "I will always be a burden on the people who matter to me"). Overall, the strong correlations between the HILL, GDS, and INQPB may suggest a lack of discriminant validity in the HILL/HILL-S. However, the BHS (the gold standard) also exhibits very strong relations with the GDS and INQ-PB. Taken together, these findings may suggest a lack of discriminant validity among all of these assessment tools. For instance, the INQ-PB contains items that, in addition to acute feelings of burden, also seem to assess future-oriented, hopeless thoughts regarding burdensomeness (e.g., "These days, the people in my life would be better off if I was gone"). On the other hand, a high degree of overlap between these constructs is not unexpected, given that hopelessness, depression, and perceived burdensomeness frequently co-occur and each of the constructs reflects negative affect.

Two versions of the new hopelessness measure are presented in the current study. Based on expert review, factor analysis, descriptive statistics, and Pearson's correlations, both versions of the scale appear to be reliable and valid assessment tools for hopelessness in later life. The HILL-S, a briefer measure, excludes items that may tap constructs other than hopelessness, such as optimism, hope, or legacy. In addition, there is reduced redundancy among the items in the HILL-S, as items strongly correlated with one another were trimmed from the abbreviated tool. Despite its shorter length, the HILL-S did not differ from the full-length HILL regarding its relatedness to other constructs, except for a lesser degree of relatedness with perceived 
burdensomeness. This might actually represent an advantage of the HILL-S, however, given that the correlation between the HILL and INQ-PB is quite high, suggesting a possible lack of discriminant validity. In addition, the brevity of the HILL-S may allow for greater utility in settings where time is routinely limited (e.g., primary care, long-term care facilities). The shorter length and inclusion of fewer reverse-coded items also may decrease burden and cognitive demand for frail older adults or individuals with higher levels of cognitive impairment.

Considering the many advantages of the HILL-S compared to the HILL, some may question the utility of retaining a longer version. However, in addition to creating a general measure of hopelessness, one primary purpose of the current project was to include item content that may be clinically useful in determining idiographic targets for intervention. While the items that remain on the HILL-S certainly serve this purpose, the supplementary items represented on the HILL may provide increased utility for clinicians as they conceptualize cases and design treatment plans. For example, the following item was removed from the HILL-S due to potential multidimensionality: "I feel hopeful about the legacy I have left behind." However, if an older adults responds "somewhat disagree" or "disagree" to this item, the clinician may elect to include "building legacy" as a target of intervention. There are a plethora of treatment approaches where such information would be applicable, including virtually any intervention for depression or suicidality. For example, in traditional cognitive-behavioral therapy for late-life depression (e.g., Gallagher-Thompson, Steffen, \& Thompson, 2008), recording a memoir could represent a mastery or pleasant event in behavioral activation. Further, thoughts such as "no one will remember me when I'm gone" (HILL item 12) may be recognized as targets for cognitive restructuring. If an older adult identifies "leaving a legacy" as a personal value, the "committed action" portion of Acceptance and Commitment Therapy (e.g., Luoma, Hayes, \& Walser, 2007) 
could include value-consistent goals such as sharing a fond memory, gifting an heirloom, or working on a "grandparent's memory book." Placing legacy-related items in a "Hope Kit," might be relevant if a clinician utilizes the Collaborative Assessment and Management of Suicidality (CAMS; Jobes, 2006) protocol in working with suicidal older adults. These represent only a few examples of the potential clinical utility of the individual items on the HILL and HILL-S.

\section{Limitations}

Despite the strengths of the HILL and HILL-S outlined here, there are a number of limitations to the present study. A few of these limitations revolve around the sample. For instance, the sample is overwhelmingly comprised of Caucasian individuals. In addition, the present study did not target cognitively impaired older adults, individuals in medical or psychiatric inpatient settings, or individuals in long-term care. Thus, findings from the present study may not be generalizeable to other populations of older adults or individuals with lifelimiting illness. Psychometric evaluation of the HILL/HILL-S in other, diverse populations and settings is certainly a direction for future studies. It is noteworthy, however, that the present sample is diverse in terms of age, geography, rurality, education, and marital status. Further, the recruitment of older adults through multiple strategies is viewed as a strength of the study, given that participants are likely diverse in terms of the incorporation of technology into daily life.

Other limitations of the current project involve its cross-sectional design and solely selfreport format. For instance, prospective studies have demonstrated that higher scores on the BHS are a significant predictor of subsequent suicidal behavior, including attempts and deaths. In addition, prospective studies have allowed for the rigorous evaluation of clinical cut-off scores on the measure. Such analyses could not be conducted with the HILL/HILL-S in the present 
study due to the nature of the study design. Furthermore, because the current study was an anonymous survey battery, it represents a multitrait-monomethod design, whereas multitraitmultimethod designs are preferable. In order to further examine the scales' validity, future studies might include clinician rating scales or diagnostic interviews in the study measures. These limitations notwithstanding, the preliminary, cross-sectional analyses presented here provide initial evidence that both versions of the HILL are reliable and valid measures of hopelessness in later life, and are worth evaluating with more complex study designs and analyses in the future.

\section{Conclusion}

At present, many researchers propose that some degree of hopelessness is inherent or expected in aging. Perhaps there is some truth in this assertion, but only if hopelessness is defined by one's situation rather than by one's cognitive style or outlook regarding a given situation. For instance, many people are faced with realistically hopeless situations (e.g., renal failure); nonetheless, these individuals still may be hopeful about the dying process, legacy, or pain management. A primary purpose of the HILL and its abbreviated version is to offer assessment options that do not conflate hopeless situations with hopeless cognitive styles among older adults and individuals with life-limiting illness. The HILL also includes thematic content pertinent to aging individuals. This aspect of the instrument may make it more likely to detect hopelessness among older adults, if hopelessness is present. For instance, an older adult may not identify with general feelings of pessimism, but may endorse feeling hopeless about social support or the dying process. This characteristic of the HILL/HILL-S highlights the notion that hopelessness represents a spectrum rather than a dichotomy. Furthermore, as discussed above, individual item responses may be used to design individualized interventions for hopelessness 
and related constructs such as depression and suicidality. Fortunately, Fiske and Arbore (20002001) have provided initial evidence that late-life hopelessness is an appropriate target for intervention. Their intervention resulted in a significant reduction for hopelessness with as little involvement as weekly telephone contact with suicidal older adults. Certainly, one could hypothesize that other psychosocial therapies would demonstrate similar positive results for hopelessness and suicidality (e.g., cognitive-restructuring, behavioral activation, time-limited dynamic therapy). However, these also need to be put to the empirical test. 


\section{References}

Abramson, L. Y., Metalsky, G. I., \& Alloy, L. B. (1989). Hopelessness depression: A theorybased subtype of depression. Psychological Review, 96(2), 358-372. doi: 10.1037//0033295X.96.2.358

Aish, A., \& Wasserman, D. (2001). Does Beck's Hopelessness Scale really measure several components? Psychological Medicine, 31(2), 367-372. doi: $10.1017 / \mathrm{S} 0033291701003300$

Anda, R., Williamson, D., Jones, D., Macera, C., Eaker, E., Glassman, A., \& Marks, J. (1993). Depressed affect, hopelessness, and the risk of ischemic heart disease in a cohort of U.S. adults. Epidemiology, 4(4), 285-294. doi: 10.1097/00001648-199307000-00003

Bamonti, P. M., Price, E. C., \& Fiske, A. (2013). Depressive symptoms and suicide risk in older adults: Value placed on autonomy as a moderator for men but not women. Suicide and Life-Threatening Behavior. doi: 10.1111/sltb.12062

Beck, A. T. (1963). Thinking and depression. Archives of General Psychiatry, 9, 324-333. doi: 10.1001/archpsyc. 1964.01720240015003

Beck A. T., \& Beck R. W. (1972). Screening depressed patients in family practice: A rapid technique. Postgraduate Medicine, 52, 81-85.

Beck, A. T., Brown, G., Berchick, R. J., Stewart, B. L., \& Steer, R. A. (1990). Relationship between hopelessness and ultimate suicide: A replication with psychiatric outpatients. The American Journal of Psychiatry, 147(2), 190-195.

Beck, A. T., Kovacs, M., \& Weissman, A. (1975). Hopelessness and suicidal behavior: An overview. Journal of the American Medical Association, 234(11), 1146-1149. doi: 10.1001/jama.234.11.1146 
Beck, A. T., Kovacs, M., \& Weissman, A. (1979). Assessment of suicidal intention: The Scale for Suicide Ideation. Journal of Consulting and Clinical Psychology, 47, 434-452. doi: 10.1037//0022-006X.47.2.343

Beck, A. T. \& Steer, R. A. (1990). Manual for the Beck Anxiety Inventory. Psychological Corporation: San Antonio, TX.

Beck, A. T., Steer, R. A., Beck, J. S., \& Newman, C. F. (1993). Hopelessness, depression, suicidal ideation, and clinical diagnosis of depression. Suicide and Life-Threatening Behavior, 23, 139-145.

Beck, A. T., Steer, R. A., Kovacs, M., \& Garrison, B. (1985). Hopelessness and eventual suicide: A 10-year prospective study of patients hospitalized with suicidal ideation. American Journal of Psychiatry, 142, 559-563.

Beck, A.T., Weissman, A., Lester, D., Trexler, L. (1974). The measurement of pessimism: The Hopelessness Scale. Journal of Consulting and Clinical Psychology, 42, 861-865. doi: $10.1037 / \mathrm{h} 0037562$

Bédard, M., Molloy, D., Squire, L., Minthorn-Biggs, M., Dubois, S., Lever, J. A., \& O'Donnell, M. (2003). Validity of self-reports in dementia research: The Geriatric Depression Scale. Clinical Gerontologist: The Journal of Aging And Mental Health, 26(3-4), 155-163. doi: 10.1300/J018v26n03_13

Benzein, E. G., \& Berg, A. C. (2005). The level of and relation between hope, hopelessness and fatigue in patients and family members in palliative care. Palliative Medicine, 19(3), 234240. doi:10.1191/0269216305pm1003oa 
Berlau, D. J., Corrada, M. M., Peltz, C. B., \& Kawas, C. H. (2012). Disability in the oldest-old: Incidence and risk factors in The 90+ study. The American Journal of Geriatric Psychiatry, 20(2), 159-168. doi: 10.1097/JGP.0b013e31820d9295

Bertolote, J.M. (2001). Suicide in the world: an epidemiological overview 1959-2000. In: Wasserman, D. (Ed.), Suicide: An Unnecessary Death. London, UK: Martin Dunitz. doi: $10.1201 / \mathrm{b} 14713-3$

Breitbart, W., Rosenfeld, B, Pessin, H., Kaim, H., Funesti-Esch, K., Galietta, M., Nelson, C. J., \& Brescia, R. (2000). Depression, hopelessness, and desire for hastened death in terminally ill patients with cancer. Journal of the American Medical Association, 284(22), 2907-2911. doi: 10.1001/jama.284.22.2907

Britton, P. C., Duberstein, P. R., Conner, K. R., Heisel, M. J., Hirsch, J. K., \& Conwell, Y. (2008). Reasons for living, hopelessness, and suicide ideation among depressed adults 50 years or older. American Journal of Geriatric Psychiatry, 16(9), 736-741). doi: 10.1097/JGP.0b013e31817b609a

Byrne, G. J., \& Pachana, N. A. (2011). Development and validation of a short form of the Geriatric Anxiety Inventory-the GAI-SF. International Psychogeriatrics, 23, 125-131. doi: $10.1017 / \mathrm{S} 1041610210001237$

Campbell, D. T., \& Fiske, D. W. (1959) Convergent and discriminant validation by the multitrait- multimethod matrix. Psychological Bulletin, 56, 81-105. doi: $10.1037 / \mathrm{h} 0046016$

Carstensen, L. L., \& Mikels, J. A. (2005). At the intersection of emotion and cognition: Aging and the positivity effect. Current Directions in Psychological Science, 14(3), 117-121. doi: 10.1111/j.0963-7214.2005.00348.x 
Chan, J., Draper, B., \& Banerjee, S., (2007). Deliberate self-harm in older adults: a review of the literature from 1995 to 2004. International Journal of Geriatric Psychiatry, 22, 720-732. doi: $10.1002 / g p s .1739$

Chan, S., Hadjistavropoulos, T., Carleton, R., \& Hadjistavropoulos, H. (2012). Predicting adjustment to chronic pain in older adults. Canadian Journal of Behavioural Science/Revue Canadienne Des Sciences Du Comportement, 44(3), 192-199. doi: $10.1037 / \mathrm{a} 0028370$

Chochinov, H. M., Wilson, K. G., Enns, M., \& Lander, S. (1998). Depression, hopelessness, and suicidal ideation in the terminally ill. Psychosomatics, 39, 366-370. doi: $10.1016 / \mathrm{S} 0033-3182(98) 71325-8$

Christian, L. M., Glaser, R., Porter, K., Malarkey, W. B., Beversdorf, D., \& Kiecolt-Glaser, J. K. (2011). Poorer self-rated health is associated with elevated inflammatory markers among older adults. Psychoneuroendocrinology, 36(10), 1495-1504. doi:10.1016/j.psyneuen.2011.04.003

Clark, L., \& Watson, D. (1995). Constructing validity: Basic issues in objective scale development. Psychological Assessment, 7(3), 309-319. doi: 10.1037/1040-3590.7.3.309

Cochrane-Brink, K. A., Lofchy, J. S., \& Sakinofsky, I. (2000). Clinical rating scales in suicide risk assessment. General Hospital Psychiatry, 22(6), 445-451. doi: 10.1016/S01638343(00)00106-7

Cole, D. A. (1988). Hopelessness, social desirability, depression, and parasuicide in two college student samples. Journal of Consulting and Clinical Psychology, 56(1), 131-136. doi:10.1037/0022-006X.56.1.131 
Conner, K. R., Duberstein, P. R., Conwell, Y., Seidlitz, L., \& Caine, E. D. (2001). Psychological vulnerability to completed suicide: A review of empirical studies. Suicide and LifeThreatening Behavior, 31(4), 367-385. doi: 10.1521/suli.31.4.367.22048

Conrad, A. K., Jacoby, A. M., Jobes, D. A., Lineberry, T. W., Shea, C. E., Arnold Ewing, T. D., ... \& Kung, S. (2009). A psychometric investigation of the Suicide Status Form II with a psychiatric inpatient sample. Suicide and Life-Threatening Behavior, 39(3), 307-320. doi: 10.1521/suli.2009.39.3.307

Conwell, Y., Duberstein, P. R., Conner, K., Eberly, S., Cox, C., \& Caine, E. D. (2002). Access to firearms and risk for suicide in middle-aged and older adults. American Journal of Geriatric Psychiatry, 10(4), 407-416. doi: 10.1176/appi.ajgp.10.4.407

Cortina, J. M. ( 1993). What is coefficient alpha? An examination of theory and applications. Journal of Applied Psychology, 78, 98- 104. doi: 10.1037/0021-9010.78.1.98

Crowne, D. P., \& Marlowe, D. (1960). A new scale of social desirability independent of psychopathology. Journal of Consulting Psychology, 24, 349-354. doi: $10.1037 / \mathrm{h} 0047358$

Crowne, D. P., \& Marlowe, D. (1964). The approval military. New York, NY: Wiley. Cukrowicz, K. C., Cheavens, J. S., Van Orden, K. A., Ragain, R. M., \& Cook, R. L. (2011). Perceived burdensomeness and suicide ideation in older adults. Psychology and Aging, 26(2), 331-338. doi: 10.1037/a0021836

Cukrowicz, K. C., Jahn, D. R., Graham, R. D., Poindexter, E. K., \& Williams, R. B. (2013). Suicide risk in older adults: Evaluating models of risk and predicting excess zeros in a primary care sample. Journal of Abnormal Psychology, 122(4), 1021-1030. doi:10.1037/a0034953 
D’Ath, P., Katona, P., Mullan, E., Evans, S., \& Katona. C. (1994). Screening, detection and management of depression in elderly primary care attenders: The acceptability and performance of the 15 item Geriatric Depression Scale (GDS15) and the development of short versions. Family Practice, 11, 260-266. doi: 10.1093/fampra/11.3.260

De Leo, D., Draper, B. M., Snowdon, J., \& Kõlves, K. (2013). Suicides in older adults: A case control psychological autopsy study in Australia. Journal of Psychiatric Research, 47(7), 980-988. doi:10.1016/j.jpsychires.2013.02.009

DeVellis, R. F. (2012). Scale development: Theory and applications ( $3^{\text {rd }}$ ed.). Thousand Oaks, CA: Sage.

Durham, T.W. (1982). Norms, reliability and item analysis of the hopelessness scale in general, psychiatric, forensic psychiatric, and college populations. Journal of Clinical Psychology, 38(3), 597-600. doi: 10.1002/1097-4679(198207)38:3\%3C597::AIDJCLP2270380321\%3E3.0.CO;2-6

Dyer, J. A. T., \& Kreitman, N. (1984). Hopelessness, depression, and suicidal intent in parasuicide. British Journal of Psychiatry, 144, 127-133. doi: 10.1192/bjp.144.2.127

Edwards, L. K. (1957). The social desirability variable in personality assessment and research. New York, NY: Dryden Press.

Endicott, J., \& Spitzer, R. L. (1978). A diagnostic interview: The Schedule for Affective Disorders and Schizophrenia. Archives of General Psychiatry, 35, 837-844. doi: 10.1001/archpsyc.1978.01770310043002

Everson, S. A., Goldberg, D. E., Kaplan, G. A., \& Cohen, R. D. (1996). Hopelessness and risk of mortality and incidence of myocardial infarction and cancer. Psychosomatic Medicine, $58(2), 113-121$ 
Fischer, D. G., \& Fick, C. (1993). Measuring social desirability: Short forms of the Marlowe Crowne Social Desirability Scale. Educational and Psychological Measurement, 53, 417-424. doi: 10.1177/0013164493053002011

Fisher, G. (1967). Normative and reliability data for the standard and the cross-validated Marlowe-Crowne Social Desirability Scale. Psychological Reports, 20, 174. doi: 10.2466/pr0.1967.20.1.174

Fiske, A., \& Arbore, P. (2000-2001). Future directions in late life suicide prevention. Omega: Journal of Death and Dying, 42(1), 37-53.

Folstein, M. F., Folstein, S, E., \& McHugh, P. R. (1975). "Mini-mental state": A practical method for grading the cognitive state of patients for the clinician. Journal of Psychiatric Research, 12, 189-198.

Friedman, B., Heisel, M. J., \& Delavan, R. L. (2005). Psychometric properties of the 15-item Geriatric Depression Scale in functionally impaired, cognitively intact, communitydwelling elderly primary care patients. Journal of the American Geriatrics Society, 53, 1570-1576. doi: 10.1111/j.1532-5415.2005.53461.x

Fry, P. S. (1984). Development of a geriatric scale of hopelessness: Implications for counseling and intervention with the depressed elderly. Journal of Counseling Psychology, 31, 322331. doi: 10.1037/0022-0167.31.3.322

Gallagher-Thompson, D., Steffen, A. M., \& Thompson, L. W. (2008). Handbook of behavioral and cognitive therapies with older adults. New York, NY US: Springer Science + Business Media. doi:10.1007/978-0-387-72007-4

Gallo, J. J., Bogner, H. R., Morales, K. H., Post, E. P., Have, T., \& Bruce, M. L. (2005). Depression, cardiovascular disease, diabetes, and two-year mortality among older, 
primary-care patients. The American Journal of Geriatric Psychiatry, 13(9), 748-755. doi: 10.1176/appi.ajgp.13.9.748

Gerolimatos, L. A., Gregg, J. J., \& Edelstein, B. A. (2013). Assessment of anxiety in long-term care: Examination of the Geriatric Anxiety Inventory (GAI) and its short form. International Psychogeriatrics, 25(9), 1533-1542. doi: 10.1017/S1041610213000847

Greene, S. M. (1981). Levels of measured hopelessness in the general population. British Journal of Clinical Psychology, 20, 11-14. doi: 10.1111/j.2044-8260.1981.tb00490.x

Gum, A. M., King-Kallimanis, B., and Kohn, R. (2009). Prevalence of mood, anxiety, and substance-abuse disorders for older Americans in the national comorbidity surveyreplication. The American Journal of Geriatric Psychiatry, 17, 769-781. doi:10.1097/JGP.0b013e3181ad4f5a.

Haynes, S. N., Richard, D. S., \& Kubany, E. S. (1995). Content validity in psychological assessment: A functional approach to concepts and methods. Psychological Assessment, 7(3), 238-247. doi: 10.1037//1040-3590.7.3.238

Hayslip, B., Lopez, F. G., Nation, P. (1991). Hopelessness in community-residing aged persons: a viable construct? Journal of Personality Assessment, 57, 498-505. doi: 10.1207/s15327752jpa5703_8

Heimberg, L. (1961). Development and construct validation of an inventory for the measurement of future time perspective. Unpublished master's thesis, Vanderbilt University.

Heisel, M. J., \& Flett, G. L. (2005). A psychometric analysis of the Geriatric Hopelessness Scale (GHS): Towards improving assessment of the construct. Journal of Affective Disorders, 87, 211-220. doi: 10.1016/j.jad.2005.03.016 
Heisel, M. J., \& Flett, G. L. (2006). The development and initial validation of the Geriatric Suicide Ideation Scale (GSIS). American Journal of Geriatric Psychiatry, 14, 742-751. doi: 10.1097/01.JGP.0000218699.27899.f9

Herrmann, N., Mittmann, N., Silver, I. L., \& Shulman, K. I. (1996). A validation study of the Geriatric Depression Scale Short Form. International Journal of Geriatric Psychiatry, 11, 457-460. doi: 10.1002/(SICI)1099-1166(199605)11:5\%3C457::AIDGPS325\%3E3.3.CO;2-U

Hill, R. D., Gallagher, D., Thompson, L. W., \& Ishida, T. (1988). Hopelessness as a measure of suicidal intent in the depressed elderly. Psychology and Aging, 3(3), 230-232. doi: 10.1037//0882-7974.3.3.230

Hunter, E. G. (2007). Beyond death: Inheriting the past and giving to the future, transmitting the legacy of one's self. Omega: Journal of Death \& Dying, 56(4), 313-329. doi: 10.2190/OM.56.4.a

Idler, E. L. \& Benyamini, Y. (1997). Self-rated health and mortality: A review of twenty-seven community studies. Journal of Health and Social Behavior, 38(1), 21-37. doi: $10.2307 / 2955359$

Ivanoff, A., \& Jang, S. (1991). The role of hopelessness and social desirability in predicting suicidal behavior: A study of prison inmates. Journal of Consulting And Clinical Psychology, 59(3), 394-399. doi: 10.1037//0022-006X.59.3.394

Jobes, D. A. (2006). Managing Suicidal Risk: A Collaborative Approach. New York, NY US: Guilford Press.

Koenig, H. G., Westlund, R. E., George, L. K., \& Hughes, D. C. (1993). Abbreviating the Duke Social Support Index for use in chronically ill elderly individuals. Psychosomatics: 
Journal of Consultation Liaison Psychiatry, 34(1), 61-69. doi:10.1016/S00333182(93)71928-3

Landerman, R., George, L. K., Campbell, R. T., \& Blazer, D. G. (1989). Alternative models of the stress buffering hypothesis. American Journal of Community Psychology, 17(5), 625642. doi:10.1007/BF00922639

Lang, F. R. \& Carstensen, L. L. (2002). Time counts: Future time perspective, goals, and social relationships. Psychology and Aging, 17, 125 - 139. doi: 10.1037//0882-7974.17.1.125

Lima-Costa, M. F., Cesar, C. C., Chor, D., \& Proietti, F. A. (2012). Self-rated health compared with objectively measured health status as a tool for mortality risk screening in older adults: 10-year follow-up of the Bambuí Cohort Study of Aging. American Journal of Epidemiology, 175(3), 228-235. doi: 10.1093/aje/kwr290

Linehan, M. M., \& Nielsen, S. L. (1981). Assessment of suicide ideation and parasuicide: Hopelessness and social desirability. Journal of Consulting And Clinical Psychology, 49(5), 773-775. doi: 10.1037//0022-006X.49.5.773

Luoma, J. B., Hayes, S. C., \& Walser, R. D. (2007). Learning ACT: An Acceptance \& Commitment Therapy Skills-Training Manual for Therapists. New Harbinger Publications.

Marc, L. G., Raue, P. J., \& Bruce, M. L. (2008). Screening performance of the Geriatric Depression Scale (GDS-15) in a diverse elderly home care population. American Journal of Geriatric Psychiatry, 16, 914-921. doi: 10.1097/JGP.0b013e318186bd67

Meeks, S., \& Tennyson, K. B. (2003). Depression, hopelessness, and suicidal ideation in nursing home residents. Journal of Mental Health and Aging, 9(2), 85-96. 
Missler, M., Stroebe, M., Lilian, G., Mastenbroek, M., Chmoun, S., \& van der Houwen, K. (2011). Exploring death anxiety among elderly people: A literature review and empirical investigation. Omega: Journal Of Death And Dying, 64(4), 358-379. doi: 10.2190/OM.64.4.e

Nadorff, M. R., Fiske, A., Sperry, J. A., Petts, R., \& Gregg, J. J. (in press). Insomnia symptoms, nightmares, and suicidal ideation in older adults. Journals of Gerontology: Psychological Sciences. doi: 10.1093/geronb/gbs061

Neufeld, E., O’Rourke, N., \& Donnelly, M. (2010). Enhanced measurement sensitivity of hopeless ideation among older adults at risk of self-harm: Reliability and validity of Likert-type responses to the Beck Hopelessness Scale. Aging and Mental Health, 14(6), 752-756. doi: 10.1080/13607860903421052

Neufeld, E., \& O’Rourke, N. (2009). Impulsivity and hopelessness as predictors of suiciderelated ideation among older adults. Canadian Journal of Psychiatry, 54(10), 684-692.

O'Riley, A. A. \& Fiske, A. (2012). Emphasis on autonomy and propensity for suicidal behavior in younger and older adults. Suicide and Life-Threatening Behavior, 42, 394-404. 10.1111/j.1943-278X.2012.00098.x

Osman, A., Bagge, C. L., Gutierrez, P. M., Konick, L. C., Kopper, B. A., \& Barrios, F. X. (2001). The Suicidal Behaviors Questionnaire--Revised (SBQ-R): Validation with clinical and nonclinical samples. Assessment, 8(4), 443-454. doi:10.1177/107319110100800409

Paulhus, D. L. (1991). Measurement and control of response bias. In J. P. Robinson, P. R. Shaver, L. S. Wrightsman (Eds.), Measures of Personality and Social Psychological 
Attitudes, Volume I, (pp. 17-59). San Diego, CA: Academic Press. doi: 10.1016/B978-0$12-590241-0.50006-X$

Petrie, K., \& Chamberlain, K. (1983). Hopelessness and social desirability as moderator variables in predicting suicidal behavior. Journal of Consulting And Clinical Psychology, 51(4), 485-487. doi: 10.1037//0022-006X.51.4.485

Plassman, B. L., Langa, K. M., Fisher, G. G., Heeringa, S. G., Weir, D. R., Ofstedal, M. B., \& ... Wallace, R. B. (2007). Prevalence of dementia in the United States: The aging, demographics, and memory study. Neuroepidemiology, 29(1-2), 125-132. doi: $10.1159 / 000109998$

Powers, J. R., Goodger, B., \& Byles, J. E. (2004). Assessment of the abbreviated Duke Social Support Index in a cohort of older Australian women. Australasian Journal on Ageing, 23(2), 71-76. doi:10.1111/j.1741-6612.2004.00008.x

Preacher, K. J., \& Hayes, A. F. (2008). Asymptotic and resampling strategies for assessing and comparing indirect effects in multiple mediator models. Behavior Research Methods, 40(3), 879-891. doi:10.3758/BRM.40.3.879

Radloff, L. (1977). The CES-D scale: A self report depression scale for research in the general population. Applied Psychological Measurement, 1, 385-401.

Reynolds, W. M. (1982). Development of reliable and valid short forms of the MarloweCrowne Social Desirability Scale. Journal of Clinical Psychology, 38, 119-125. doi: 10.1002/1097-4679(198201)38:1\%3C119::AID-JCLP2270380118\%3E3.0.CO;2-I

Rifai, A. H., George, C. J., Stack, J. A., Mann, J. J., \& Reynolds, C. F. (1994). Hopelessness in suicide attempters after acute treatment for depression in late life. The American Journal of Psychiatry, 151, 1687-1690. 
Ron, P. (2004). Depression, hopelessness, and suicidal ideation among the elderly: A comparison between men and women living in nursing homes and in the community. Journal of Gerontological Social Work, 43(2-3), 97-116. doi: 10.1300/J083v43n02_07

Rosenfeld, B., Breitbart, W., Gibson, C., Kramer, M., Tomarken, A., Nelson, C., Pessin, H.... Schuster, M. (2006). Desire for hastened death among patients with advanced AIDS. Psychosomatics, 47(6), 504-512. doi: 10.1176/appi.psy.47.6.504

Rowe, J. W., \& Kahn, R. L. (1997). Successful aging. The Gerontologist, 37(4), 433-440. doi: 10.1093/geront/37.4.433

Sheikh, J. A., \& Yesavage, J. A. (1986). Geriatric Depression Scale (GDS): Recent findings and development of a shorter version. In T. L. Brink (Ed.), Clinical gerontology: A guide to assessment and intervention (p. 165-173). New York: Howarth Press.

Snyder, C. R., Harris, C., Anderson, J. R., Holleran, S. A., Irving, L. M., Sigmon, S. T., \& ... Harney, P. (1991). The will and the ways: Development and validation of an individualdifferences measure of hope. Journal of Personality And Social Psychology, 60(4), 570585. doi:10.1037/0022-3514.60.4.570

Spielberger, C.D., Gorsuch, R.R., \& Luchene, R.E. (1970). The State-Trait Anxiety Inventory. Palo Alto, CA: Consulting Psychologists Press. doi: 10.1002/9780470479216.corpsy0943

Steed, L. (2001). Further validity and reliability evidence for Beck Hopelessness Scale scores in a nonclinical sample. Educational And Psychological Measurement, 61(2), 303-316. doi: $10.1177 / 00131640121971121$

Stern, S. L., Dhanda, R., \& Hazuda, H. P. (2001). Hopelessness predicts mortality in older Mexican and European Americans. Psychosomatic Medicine, 63(3), 344-351.

Stotland, E. (1969). The Psychology of Hope. San Francisco, CA: Jossey-Bass. 
Strahan, R., \& Gerbasi, K. C. (1972). Short, homogeneous versions of the Marlowe-Crowne Social Desirability Scale. Journal of Clinical Psychology, 28, 191-193. doi: 10.1002/1097-4679(197204)28:2\%3C191::AID-JCLP2270280220\%3E3.0.CO;2-G

Streiner, D. L. \& Norman, G. R. (2003). Health measurement scales: A practical guide to their development and use ( ${ }^{\text {rd }}$ Edition). Oxford University Press: Oxford, NY.

Szanto, K., Reynolds, C. F., Conwell, Y., Begley, A. E., \& Houck, P. (1998). High levels of hopelessness persist in geriatric patients with remitted depression and a history of attempted suicide. Journal of the American Geriatrics Society, 46(11), 1401-1406.

Tabachnick, B. G., \& Fidell, L. S. (2007). Using multivariate statistics (5th ed.). Boston, MA: Allyn \& Bacon/Pearson Education.

Thomsen, D., Mehlsen, M., Viidik, A., Sommerlund, B., \& Zachariae, R. (2005). Age and gender differences in negative affect--Is there a role for emotion regulation? Personality and Individual Differences, 38(8), 1935-1946. doi:10.1016/j.paid.2004.12.001

Trenteseau, J. A., Hyer, L., Verenes, D., \& Warsaw, J. (1989). Hopelessness among later-life patients. The Journal of Applied Gerontology, 8(3), 355-364. doi:

$10.1177 / 073346488900800306$

Uncapher, H., Gallagher-Thompson, D., Osgood, N. J., \& Bongar, B. (1998). Hopelessness and suicidal ideation in older adults. The Gerontologist, 38(1), 62-70. doi: $10.1093 /$ geront/38.1.62

Van Orden, K. A., Witte, T. K., Cukrowicz, K. C., Braithwaite, S., Selby, E. A., \& Joiner, T. E. (2010). The Interpersonal Theory of Suicide. Psychological Review, 117(2), 575-600. doi: $10.1037 / \mathrm{a} 0018697$ 
Van Orden, K. A., Witte, T. K., Gordon, K. H., Bender, T. W., \& Joiner, T. E. (2008). Suicidal desire and the capability for suicide: Tests of the interpersonal-psychological theory of suicidal behavior among adults. Journal of Consulting \& Clinical Psychology, 76, 7283. doi: 10.1037/0022-006X.76.1.72

Webster, C., \& Bryan, K. (2009). Older people's views of dignity and how it can be promoted in a hospital environment. Journal of Clinical Nursing, 18(12), 1784-1792. doi: 10.1111/j.1365-2702.2008.02674.x

Weishaar, M. E., \& Beck, A. T. (1992). Hopelessness and suicide. International Review of Psychiatry, 4(2), 177-184. doi: 10.3109/09540269209066315

Wetzel, R. D., Marguiles, T., Davis, R., \& Karam, E. (1980). Hopelessness, depression, and suicide intent. Journal of Consulting and Clinical Psychology, 41, 159-160. doi: 10.1001/archpsyc.1976.01770090059005

Yesavage, J. A., Brink, T. L., Rose, T. L., Lum, O., Huang, V., Adey, M., Leirer, V. O. (1983). Development and validation of a geriatric depression screening scale: a preliminary report. Journal of Psychiatry Research, 17, 37- 49. doi: 10.1016/0022-3956(82)90033-4 
Table 1. Feedback from expert review.

\begin{tabular}{ll}
\hline Item & Mean Rating \\
\hline 1. Items relevant to construct of hopelessness. & 4.4 \\
2. Items do not conflate "hopeless situations" with hopeless cognitions & 3.6 \\
3. Thematic content is relevant to older adults. & 4.4 \\
4. Items are representative of all facets of hopelessness. & 3.6 \\
5. Each facet is well-represented in the item pool. & 3.8 \\
6. Response format is acceptable for use with older adults. & 3.4 \\
7. Self-report tool is suitable for assessment of late-life hopelessness. & 4.4 \\
8. Items are comprehensible at basic reading level. & 4.0 \\
9. Language of items is clear. & 4.4 \\
10. Items are grammatically correct. & 4.8 \\
11. Time parameters are appropriate for assessment of hopelessness. & 4.6 \\
12. HILL likely to detect hopelessness among older adults if present. & 4.4
\end{tabular}

\section{Suggestions for additional items not included in current scale:}

a. none; b. none; c. concerns about enough access, financial or otherwise, for help one might need? More on social support?; d. none; e. none

14. Recommendations for deleted items:

a. none; $b$. the two items on anticipated pain at death seem too closely worded; the burdensomeness construct seems a different construct; c. I know you have some items which seem to offer a reliability check- essentially the same. Unless for reliability purposes, I might now include them both (of course, for initial testing of the tool, include them and see which items function better...); d. Item 2- hopelessness or locus of control, Item 5- meaning in life or suicidal ideation, Item 8- locus of control, Item 9- Fear of death, Item 15- Locus of control, Item 16- Fear of death, Item 20- Social support, Item 21- Loneliness, Item 22- This seems to tap into a person's belief that he/she can cope with illness. Is that the same as hopelessness? Item 23- Is sense of burden hopelessness? Might burden be a reality in some circumstances? Item 24- again, think this conflates fear of death with hopelessness. What if someone knows they will suffer (because of painful terminal condition?), Item 25- Meaning in life? Item 26- What if 
a person isn't? Is expecting to be dependent the same as hopelessness? Item 27- This may be a reality for some people. So is that hopelessness?; e. Item 5- I am not sure I like the prompt "When my health fails..." Of course with aging health does decline but fails is a bit strong. How about "In the event my health declines,..." Item 12- I am not sure what aspect of hopelessness this item measures. It relates to leaving a legacy, but is this part of hopelessness? Item 16 \& 24- These items are almost identical. Also, how is being free of pain at death related to hopelessness? Item 20- I am not sure how this item relates to hopelessness. It seems most related to social support or isolation.

\section{Items for modifying or revising:}

a. none; $b$. The item on page 2 "I have a group of friends..." may conflate hopelessness and social support; Also, "no one will remember me or anything I've done..." Why include two phrases - risk including respondent and I think they get at two separate constructs; c. "Even though I've lived most of my life, I still have reasons to be excited about the future."

Sometimes people struggle with the term "excited"- it's a charged word. Maybe consider using a term like optimistic or positive. "The process of dying is/will be unbearable." Do you plan to keep both "is" and "will be?" Could be confusing. "If I allow myself to be hopeful again..." This question seems to assume a previous loss of hope? Do you need to have the word "again" there? Also, to me, the word "hurt" implies something interpersonal, but the hope may have been around recovering from some physical functioning. Maybe use the word "disappointment." "I feel hopeful about the legacy I have left for my family." What about people who have no family? Or only very distant relatives with whom there is minimal connection? Might you just delete "for my family?" Also, will most people know what "legacy" means? Maybe get at something broader about one's acceptance about one's life? I'm not sure if issues of integrity versus despair relate to hopelessness?; d. see above; e. see above

16. Please provide any other suggestions improving quality of the measure:

a. There is some controversy over what scales older adults prefer, $\mathrm{T} / \mathrm{F}$ versus likert. No agreement though, but be prepared to defend your decision; b. none; c. I find the task of "disagreeing" to a negative statement to be quite challenging. I'm not sure if there is research on how well older adults with MCI do on that? Overall, great work!; d. Prefer dichotomous format e.g., true/false or agree/disagree; Also, what "facets" are there in hopelessness?; e. I like the response format. If you choose to keep the Likert-type response format (and I think you should) you will probably find that cognitively impaired older adults will not do it as well as a simple yes/no format. But it will work better with intact older adults who will object to the yes/no format, so I think it is a good choice. Best of luck to you as this fine project proceeds!

Note: Rating scale for items 1-12 ranged from 1 (strongly disagree) to 5 (strongly agree) 
Table 2. Results of principal components analysis used for item selection.

\begin{tabular}{|c|c|c|c|c|c|}
\hline Item No. & Description & Factor 1 & Factor 2 & Factor 3 & Factor 4 \\
\hline 1 & Powerlessness to make changes & $.71 *$ & .24 & -.16 & .14 \\
\hline 2 & No control over future & $.69 *$ & -.19 & -.22 & .02 \\
\hline 3 & No point in trying anymore & $.81 *$ & -.18 & -.13 & .08 \\
\hline $4(\mathrm{P})$ & Still have reasons to be positive & $.60 *$ & $.40^{*}$ & -.16 & .04 \\
\hline 5 & If health declines, no reason to go on & $.66^{*}$ & -.21 & -.04 & .21 \\
\hline $6(\mathrm{P})$ & Plan to enjoy life as much as possible & $.52 *$ & $.51^{*}$ & -.02 & .00 \\
\hline 7 & Doubt situation will ever improve & $.58 *$ & -.20 & -.39 & .02 \\
\hline $8(\mathrm{P})$ & Can handle future, dealt with worse & $.60 *$ & $.46^{*}$ & -.18 & -.02 \\
\hline 9 & Process of dying will be unbearable & $.46^{*}$ & -.02 & -.20 & -.24 \\
\hline $10(\mathrm{P})$ & Know tough things can't stay that way & $.62 *$ & .39 & -.36 & .13 \\
\hline 11 & Even later, I can be useful and helpful & $.72 *$ & .28 & -.20 & .09 \\
\hline 12 & No one will remember me after gone & $.61 *$ & -.12 & .26 & $.42 *$ \\
\hline 13 & No use because won't be able to enjoy & $.83^{*}$ & -.02 & .09 & -.10 \\
\hline 14 & If hopeful, set up for disappointment & $.78^{*}$ & -.16 & .02 & -.06 \\
\hline 15 & Nothing left to look forward to & $.84^{*}$ & -.04 & -.02 & -.16 \\
\hline $16(\mathrm{P})$ & Hope that death relatively free of pain & .33 & $.43^{*}$ & $.46^{*}$ & -.26 \\
\hline 17 & Current situation is hopeless & $.85^{*}$ & -.10 & .03 & -.18 \\
\hline 18 & Future filled with dread & $.82 *$ & -.14 & .13 & -.15 \\
\hline 19 & Given up on enjoying life & $.82 *$ & -.06 & .07 & -.22 \\
\hline $20(\mathrm{P})$ & Hopeful about social support & $.47 *$ & $.40 *$ & $.43^{*}$ & .14 \\
\hline 21 & Believe will be lonely as grow older & $.67 *$ & -.25 & .15 & .18 \\
\hline $22(\mathrm{P})$ & Can do happy things despite handicap & $.63^{*}$ & .29 & .05 & -.07 \\
\hline 23 & Will always be a burden & $.71 *$ & -.08 & .09 & -.18 \\
\hline 24 & No one will remember anything done & $.67 *$ & -.26 & .24 & $.40^{*}$ \\
\hline 25 & Won't be much meaning in life & $.83^{*}$ & -.15 & .13 & -.11 \\
\hline $26(\mathrm{P})$ & Still independent in future & $.64 *$ & .36 & -.12 & .06 \\
\hline 27 & Can't envision future without pain & $.51 *$ & -.16 & -.25 & -.07 \\
\hline $28(\mathrm{P})$ & Hopeful about legacy left behind & $.58 *$ & .18 & .07 & $.50 *$ \\
\hline 29 & Little enjoyment left in life & $.67 *$ & -.19 & .15 & -.27 \\
\hline 30 & Nothing useful left to contribute & $.83^{*}$ & -.15 & .15 & -.15 \\
\hline
\end{tabular}

*factor loading $\geq 0.40$

$(\mathrm{P})=$ reverse-scored item 
Table 3. Descriptive statistics for study variables.

\begin{tabular}{|c|c|c|c|c|c|c|c|}
\hline & $M$ & SD & $\alpha$ & Min & Max & Skew & Kurtosis \\
\hline HILL & 23.65 & 18.30 & 0.96 & 0 & 87 & 0.60 & -0.53 \\
\hline HILL-S & 11.53 & 8.12 & 0.89 & 0 & 39 & 0.55 & -0.40 \\
\hline BHS & 5.84 & 5.18 & 0.91 & 0 & 20 & 0.94 & -0.03 \\
\hline GDS & 4.19 & 3.95 & 0.89 & 0 & 14 & 0.85 & -0.37 \\
\hline INQ-PB & 12.85 & 9.03 & 0.95 & 6 & 42 & 1.21 & 0.43 \\
\hline DSSI & 12.61 & 2.71 & 0.84 & 6 & 18 & -0.86 & -0.41 \\
\hline SBQR & 5.01 & 2.75 & 0.83 & 3 & 16 & 1.57 & 1.99 \\
\hline SBQR-4 & 0.66 & 1.13 & -- & 0 & 6 & 1.88 & 3.41 \\
\hline GAI & 2.01 & 2.04 & 0.89 & 0 & 5 & 0.38 & -1.53 \\
\hline SRH & 1.31 & 0.76 & -- & 0 & 3 & 0.40 & -0.04 \\
\hline HCL & 3.29 & 2.06 & 0.58 & 0 & 10 & 0.50 & 0.03 \\
\hline P1 & 3.09 & 1.13 & -- & 1 & 6 & 0.11 & -0.50 \\
\hline P2 & 2.24 & 1.07 & -- & 4 & 5 & 0.69 & -0.18 \\
\hline MCSD & 2.97 & 1.73 & 0.63 & 0 & 6 & -0.01 & -0.98 \\
\hline
\end{tabular}

Notes: HILL=Hopelessness Inventory for Later Life; HILL-S=Hopelessness Inventory for LaterLife-Shortened; BHS=Beck Hopelessness Scale; GDS=Geriatric Depression Scale; INQ-PB= Interpersonal Needs Questionnaire-Perceived Burdensomeness; DSSI=Duke Social Support Index; SBQR=Suicide Behaviors Questionnaire-Revised; SBQR-4=Item 4; GAI=Geriatric Anxiety Inventory; SRH=Self-Rated Health; HCL=Health Checklist; P1=Pain Item 1 (frequency); P2=Pain Item 2 (interference); MCSD=Marlowe-Crowne Social Desirability Scale Revised 
Table 4. Correlation matrix for study variables to examine construct validity.

\begin{tabular}{|c|c|c|c|c|c|c|c|c|c|c|c|c|c|c|}
\hline & HILL & HILL-S & BHS & GDS & INQ-PB & DSSI & SBQR & SBQR-4 & GAI & SRH & HCL & P1 & $\mathrm{P} 2$ & MCSD \\
\hline HILL-S & $.98 * *$ & - & & & & & & & & & & & & \\
\hline BHS & $.80 * *$ & $.78 * *$ & - & & & & & & & & & & & \\
\hline GDS & $.82 * *$ & $.80 * *$ & $.84 * *$ & - & & & & & & & & & & \\
\hline INQ-PB & $.82 * *$ & $.76 * *$ & $.66 * *$ & $.70 * *$ & - & & & & & & & & & \\
\hline DSSI & $-.60 * *$ & $-.58 * *$ & $-.56 * *$ & $-.62 * *$ & $-.53 * *$ & - & & & & & & & & \\
\hline SBQR & $.48 * *$ & $.48 * *$ & $.43^{* *}$ & $.49 * *$ & $.51 * *$ & $-.35 * *$ & - & & & & & & & \\
\hline SBQR-4 & $.37 * *$ & $.37 * *$ & $.33 * *$ & $.36 * *$ & $.40 * *$ & $-.25 * *$ & $.88 * *$ & - & & & & & & \\
\hline GAI & $.49 * *$ & $.49 * *$ & $.45 * *$ & $.57 * *$ & $.48 * *$ & $-.38 * *$ & $.32 * *$ & $.22 * *$ & - & & & & & \\
\hline SRH & $.41^{* *}$ & $.39 * *$ & $.36^{* *}$ & $.42 * *$ & $.36^{* *}$ & $-.27 * *$ & $.27 * *$ & $.23 * *$ & $.20 * *$ & - & & & & \\
\hline HCL & $.37 * *$ & $.36 * *$ & $.32 * *$ & $.42 * *$ & $.34 * *$ & $-.32 * *$ & $.31 * *$ & $.24 * *$ & $.30 * *$ & $.43 * *$ & - & & & \\
\hline P1 & $.26^{* *}$ & $.27 * *$ & $.22 * *$ & $.30 * *$ & $.23 * *$ & $-.17 * *$ & $.24 * *$ & $.19 * *$ & $.20 * *$ & $.44 * *$ & $.45 * *$ & - & & \\
\hline P2 & $.41 * *$ & $.41 * *$ & $.32 * *$ & $.41 * *$ & $.36 * *$ & $-.24 * *$ & $.23 * *$ & $.20 * *$ & $.25 * *$ & $.53 * *$ & $.49 * *$ & $.71 * *$ & - & \\
\hline MCSD & $-.29 * *$ & $-.29 * *$ & $-.31 * *$ & $-.39 * *$ & $-.24 * *$ & $.25 * *$ & $-.24 * *$ & $-.21 * *$ & $-.31 * *$ & -.04 & $-.18 * *$ & -.02 & -.06 & $\therefore$ \\
\hline Age & -.03 & -.03 & .00 & -.09 & -.07 & .07 & -.09 & -.07 & -.08 & .03 & -.01 & .08 & .03 & $.13^{*}$ \\
\hline
\end{tabular}

\section{$* \mathrm{p}<0.05$}

$* * \mathrm{p}<0.001$

Notes: HILL=Hopelessness Inventory for Later Life; HILL-S=Hopelessness Inventory for Later-Life-Shortened; BHS=Beck

Hopelessness Scale; GDS=Geriatric Depression Scale; INQ-PB= Interpersonal Needs Questionnaire-Perceived Burdensomeness;

DSSI=Duke Social Support Index; SBQR=Suicide Behaviors Questionnaire-Revised; SBQR-4=Item 4; GAI=Geriatric Anxiety Inventory; SRH=Self-Rated Health; HCL=Health Checklist; P1=Pain Item 1 (frequency); P2=Pain Item 2 (interference);

MCSD=Marlowe-Crowne Social Desirability Scale Revised 
Table 5. Linear regression examining interaction of HILL and GDS in predicting the SBQ-R.

\begin{tabular}{lcccc}
\hline & $\beta$ & $\mathrm{B}$ & $\mathrm{SE}$ & $\mathrm{p}$ \\
\hline Intercept & 0.00 & 4.63 & 0.19 & $<0.01$ \\
HILL & 0.22 & 0.03 & 0.01 & 0.02 \\
GDS & 0.21 & 0.15 & 0.07 & 0.03 \\
HILL x GDS & 0.19 & 0.01 & 0.00 & $<0.01$
\end{tabular}

Notes: $\mathrm{R}^{2}=0.28$; HILL=Hopelessness Inventory for Later Life; GDS=Geriatric Depression Scale; SBQ-R=Suicide Behaviors Questionnaire-Revised. 
Table 6. Linear regression examining interaction of HILL-S and GDS in predicting the SBQ-R.

\begin{tabular}{lcccc}
\hline & $\beta$ & $\mathrm{B}$ & $\mathrm{SE}$ & $\mathrm{p}$ \\
\hline Intercept & 0.00 & 4.69 & 0.19 & $<0.01$ \\
HILL-S & 0.22 & 0.07 & 0.03 & 0.01 \\
GDS & 0.23 & 0.16 & 0.06 & 0.01 \\
HILL-S x GDS & 0.17 & 0.01 & 0.00 & $<0.01$
\end{tabular}

Notes: $\mathrm{R}^{2}=0.28$; HILL-S=Hopelessness Inventory for Later Life- Shortened; GDS=Geriatric Depression Scale; SBQ-R=Suicide Behaviors Questionnaire-Revised. 
Table 7. Linear regression examining interaction of BHS and GDS in predicting the SBQ-R.

\begin{tabular}{lcccc}
\hline & $\beta$ & $\mathrm{B}$ & $\mathrm{SE}$ & $\mathrm{p}$ \\
\hline Intercept & 0.00 & 4.77 & 0.20 & $<0.01$ \\
BHS & 0.01 & 0.00 & 0.06 & 0.94 \\
GDS & 0.41 & 0.29 & 0.07 & $<0.01$ \\
BHS x GDS & 0.13 & 0.01 & 0.01 & 0.13 \\
\hline
\end{tabular}

Notes: $\mathrm{R}^{2}=0.25$; BHS=Beck Hopelessness Scale; GDS=Geriatric Depression Scale; SBQ$\mathrm{R}=$ Suicide Behaviors Questionnaire-Revised. 
Figure 1. Interaction of the HILL and the GDS in predicting SBQ-R total score.

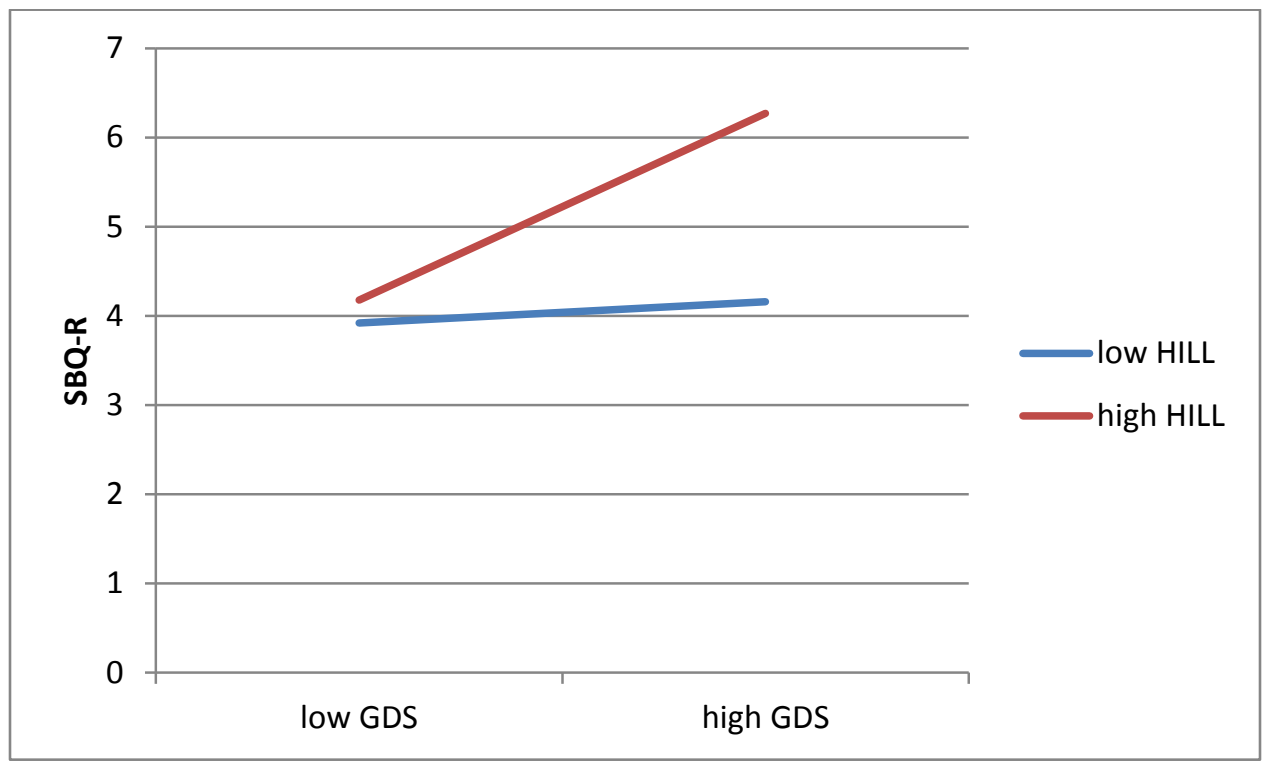

Note: HILL=Hopelessness Inventory for Later Life; GDS=Geriatric Depression Scale; SBQ$\mathrm{R}=$ Suicide Behaviors Questionnaire-Revised. 
Figure 2. Interaction of the HILL-S and the GDS in predicting SBQ-R total score.

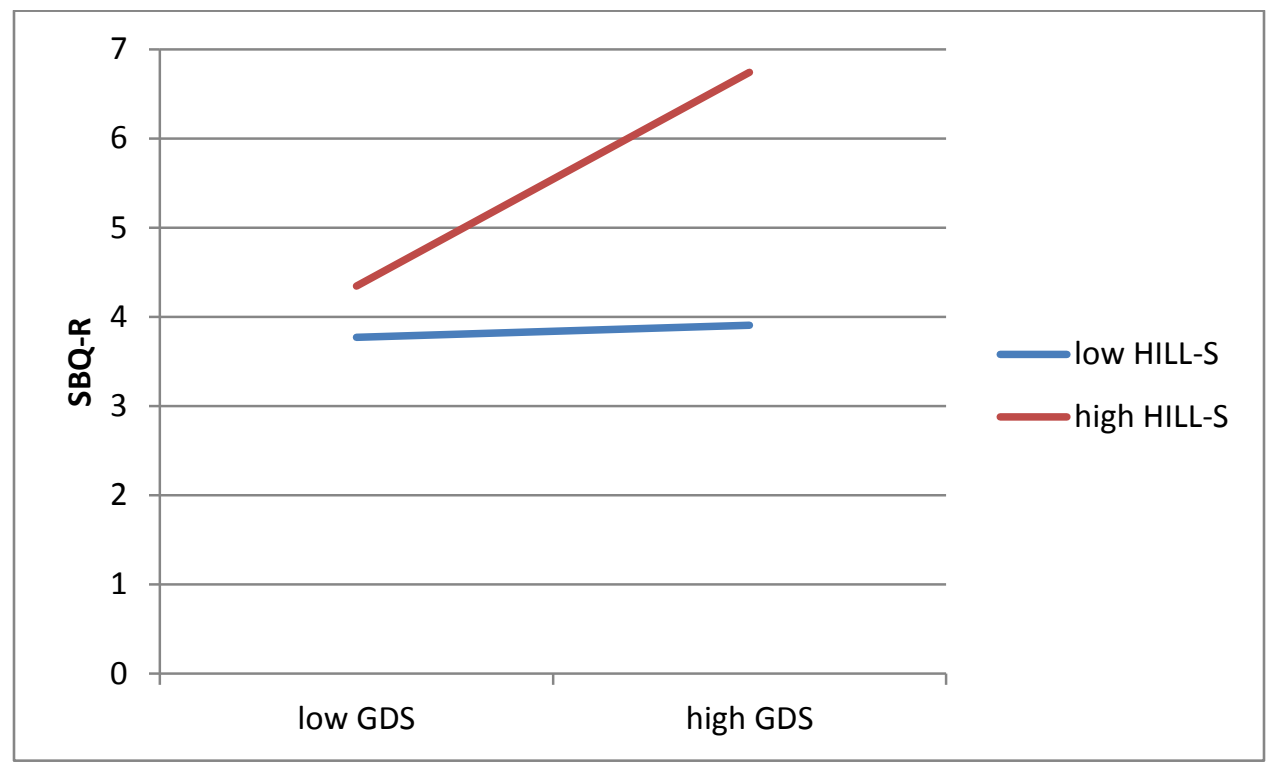

Note: HILL-S=Hopelessness Inventory for Later Life-Shortened; GDS=Geriatric Depression Scale; SBQ-R=Suicide Behaviors Questionnaire-Revised. 
Figure 3. Interaction of the BHS and the GDS in predicting SBQ-R total score.

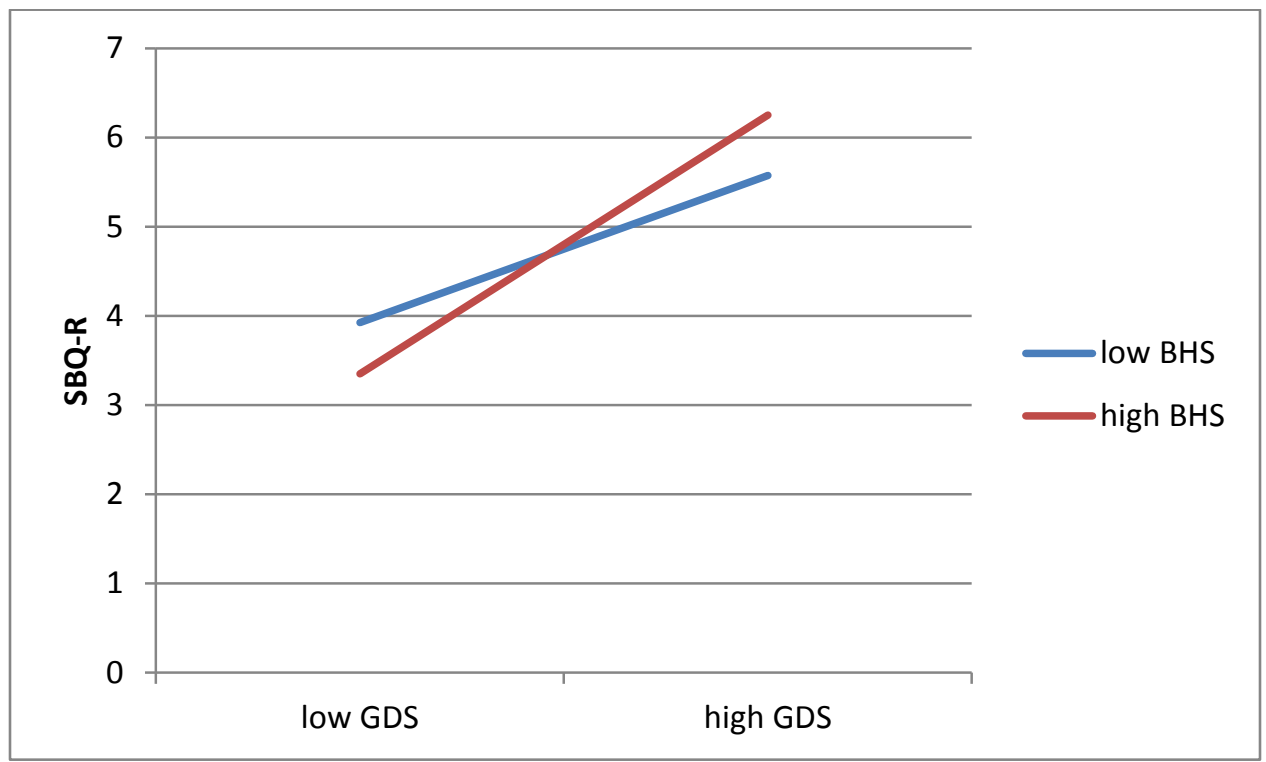

Note: BHS=Beck Hopelessness Scale; GDS=Geriatric Depression Scale; SBQ-R=Suicide Behaviors Questionnaire-Revised. 
Appendix A. HILL items for expert review.

Please rate how much you agree or disagree with each statement.

\begin{tabular}{|c|c|c|c|c|c|}
\hline No. & Item & Disagree & $\begin{array}{l}\text { Some } \\
\text { what } \\
\text { Agree }\end{array}$ & $\begin{array}{c}\text { Some } \\
\text { what } \\
\text { Disagree }\end{array}$ & Agree \\
\hline 1 & I feel powerless to make changes in my life. & & & & \\
\hline 2 & I have no control over my future. & & & & \\
\hline 3 & $\begin{array}{l}\text { There is no point in trying anymore because I } \\
\text { rarely get what I want. }\end{array}$ & & & & \\
\hline 4 & $\begin{array}{l}\text { Even though I've lived most of my life, I still } \\
\text { have reasons to be excited about the future. }\end{array}$ & & & & \\
\hline 5 & $\begin{array}{l}\text { When my health declines, I will have no reason } \\
\text { to live. }\end{array}$ & & & & \\
\hline 6 & $\begin{array}{l}\text { I plan to enjoy life as much as possible before I } \\
\text { die. }\end{array}$ & & & & \\
\hline 7 & $\begin{array}{l}\text { I doubt that my current situation will ever } \\
\text { improve. }\end{array}$ & & & & \\
\hline 8 & $\begin{array}{l}\text { I know I can handle future troubles because I've } \\
\text { dealt with worse in my past. }\end{array}$ & & & & \\
\hline 9 & The process of dying is/will be unbearable. & & & & \\
\hline 10 & $\begin{array}{l}\text { When times are tough, I know they can't stay } \\
\text { that way forever. }\end{array}$ & & & & \\
\hline 11 & $\begin{array}{l}\text { Even in my later life, I can be useful and helpful } \\
\text { to others. }\end{array}$ & & & & \\
\hline 12 & $\begin{array}{l}\text { No one will remember me or anything I've done } \\
\text { after I'm gone. }\end{array}$ & & & & \\
\hline 13 & $\begin{array}{l}\text { There is no use in trying to get something I } \\
\text { want because I won't be able to enjoy it in my } \\
\text { condition. }\end{array}$ & & & & \\
\hline 14 & $\begin{array}{l}\text { If I allow myself to feel hopeful again, I'll just } \\
\text { be setting myself up for more hurt in the future. }\end{array}$ & & & & \\
\hline
\end{tabular}




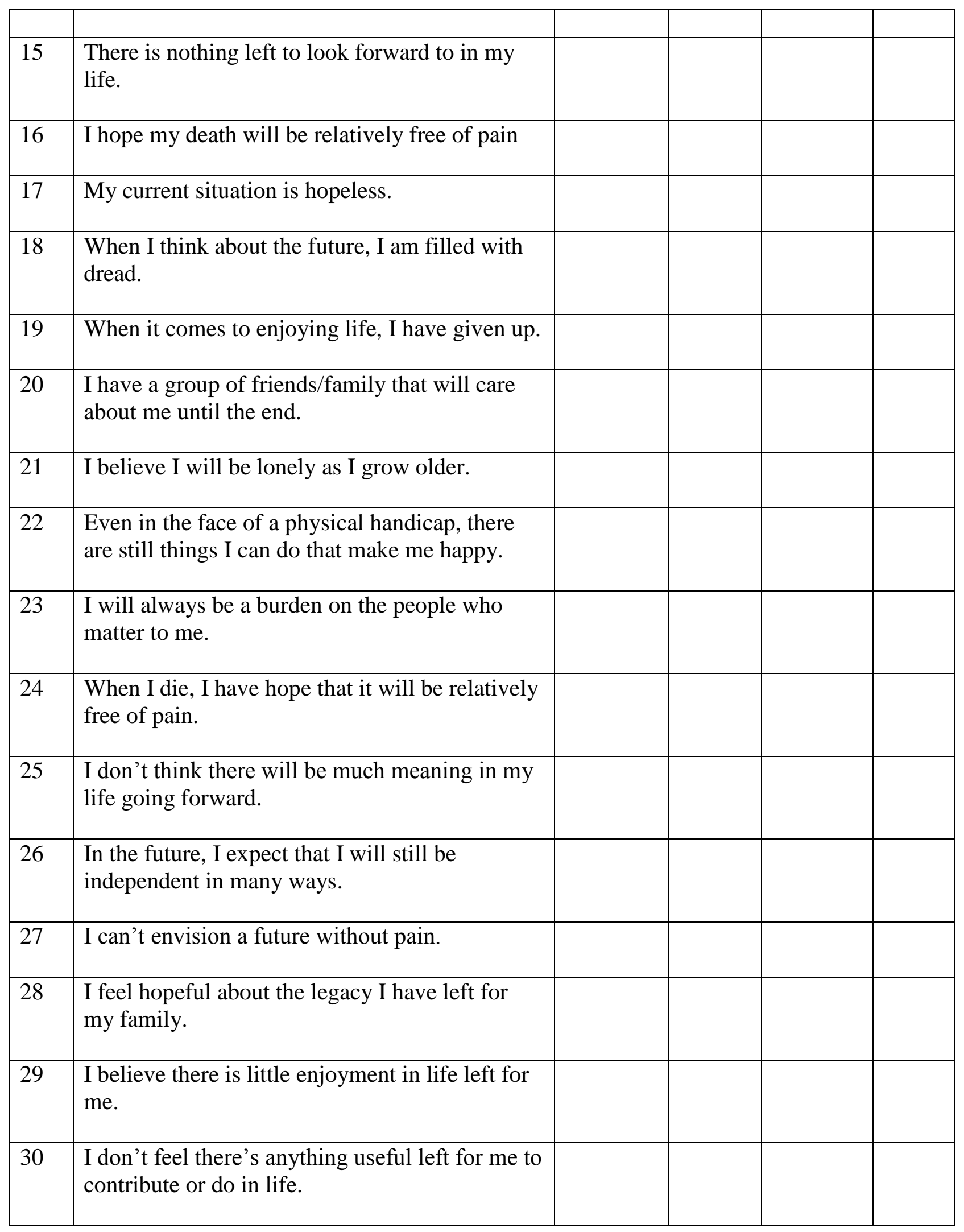




\section{Appendix B.}

Thank you for agreeing to evaluate the proposed assessment measure designed to assess hopelessness in later life. Please rate the degree to which you agree with the following statements about the Hopelessness Inventory for Later Life (HILL) and its items. Contact Jay Gregg (jgregg@mix.wvu.edu) if you have any questions about the HILL or this evaluation.

(1) The items included on the HILL are relevant to the construct of hopelessness (i.e., negative system of beliefs regarding one's self and one's future).

$\begin{array}{lllll}1 & 2 & 3 & 4 & 5\end{array}$

Strongly disagree $\quad$ Neither agree/disagree $\quad$ Strongly agree

(2) The proposed items do not conflate hopeless situations (e.g., terminal illness) with hopeless cognitions.

$\begin{array}{lllll}1 & 2 & 3 & 4 & 5\end{array}$

Strongly disagree $\quad$ Neither agree/disagree Strongly agree

(3) The HILL includes thematic content that is relevant to older adults.

$\begin{array}{lllll}1 & 2 & 3 & 4 & 5\end{array}$

Strongly disagree $\quad$ Neither agree/disagree Strongly agree

(4) The items are representative of all facets of hopelessness in later life.

$\begin{array}{lllll}1 & 2 & 3 & 4 & 5\end{array}$

Strongly disagree $\quad$ Neither agree/disagree Strongly agree

(5) Each facet of late-life hopelessness is well-represented in the HILL item pool.

$\begin{array}{lllll}1 & 2 & 3 & 4 & 5\end{array}$

Strongly disagree $\quad$ Neither agree/disagree Strongly agree

(6) The response format of the scale is acceptable for use with older adults (including individuals with mild cognitive impairment or functional limitations).

$\begin{array}{lllll}1 & 2 & 3 & 4 & 5\end{array}$

Strongly disagree $\quad$ Neither agree/disagree Strongly agree

(7) The use of a self-report measure is suitable for the function of assessing hopelessness in later life.

1

Strongly disagree
2

3

Neither agree/disagree
4

Strongly agree 
(8) The items are comprehensible at a basic reading level.

$1 \quad 2 \quad 3 \quad 4$

Strongly disagree

Neither agree/disagree
5

Strongly agree
(9) The language of the items is clear.
1

Strongly disagree
2

(1)

3

Neither agree/disagree
4

(10) The items on the HILL are grammatically correct.
4

(n)

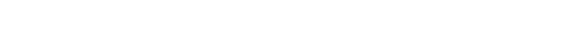

1 2

Strongly disagree

\section{3}

Neither agree/disagree
4 5 Strongly agree

(11) The time parameters used by the HILL (i.e., please rate the degree to which you agree with the following statements right now) are appropriate for assessment of hopelessness.

$\begin{array}{lllll}2 & 3 & 4 & 5\end{array}$

Strongly disagree $\quad$ Neither agree/disagree $\quad$ Strongly agree

(12) The HILL will likely detect hopelessness among older adults if it is present.

$\begin{array}{lcccc}1 & 2 & 3 & 4 & 5 \\ \text { Strongly disagree } & & \text { Neither agree/disagree } & & \text { Strongly agree }\end{array}$

(13) What suggestions do you have for additional items not included in the current scale?

(14) What items, if any, do you recommend for deletion (e.g., due to redundancy, lack of relevance, or lack of clarity)?

(15) What items, if any, do you suggest modifying or revising (e.g., due to grammatical error or clarity)?

(16) Please provide any other suggestions for improving the quality of the HILL for assessing hopelessness in later life. Any feedback is welcome and appreciated! 
Appendix C. Hopelessness Inventory for Later Life

Please rate how much you agree or disagree with each statement at the present time.

\begin{tabular}{|c|c|c|c|c|c|}
\hline No. & Item & Disagree & $\begin{array}{c}\text { Somewhat } \\
\text { Disagree }\end{array}$ & $\begin{array}{c}\text { Somewhat } \\
\text { Agree }\end{array}$ & Agree \\
\hline 1. & $\begin{array}{l}\text { I feel powerless to make changes in my } \\
\text { life. }\end{array}$ & & & & \\
\hline 2. & I have no control over my future. & & & & \\
\hline 3. & $\begin{array}{l}\text { There is no point in trying anymore } \\
\text { because I rarely get what I want. }\end{array}$ & & & & \\
\hline 4. & $\begin{array}{l}\text { Even though I've lived most of my life, I } \\
\text { still have reasons to be positive about the } \\
\text { future. }\end{array}$ & & & & \\
\hline 5. & $\begin{array}{l}\text { If my health significantly declines, I will } \\
\text { have no reason to go on. }\end{array}$ & & & & \\
\hline 6. & $\begin{array}{l}\text { I plan to enjoy life as much as possible } \\
\text { before I die. }\end{array}$ & & & & \\
\hline 7. & $\begin{array}{l}\text { I doubt that my current situation will ever } \\
\text { improve. }\end{array}$ & & & & \\
\hline 8. & $\begin{array}{l}\text { I know I can handle future troubles } \\
\text { because I've dealt with worse in my past. }\end{array}$ & & & & \\
\hline 9. & The process of dying will be unbearable. & & & & \\
\hline 10. & $\begin{array}{l}\text { When times are tough, I know they can't } \\
\text { stay that way forever. }\end{array}$ & & & & \\
\hline 11. & $\begin{array}{l}\text { Even in my later life, I can be useful and } \\
\text { helpful to others. }\end{array}$ & & & & \\
\hline 12. & No one will remember me after I'm gone. & & & & \\
\hline 13. & $\begin{array}{l}\text { There is no use in trying to get something } \\
\text { I want because I won't be able to enjoy it } \\
\text { in my condition. }\end{array}$ & & & & \\
\hline 14. & $\begin{array}{l}\text { If I allow myself to feel hopeful, I'll just } \\
\text { be setting myself up for more } \\
\text { disappointment in the future. }\end{array}$ & & & & \\
\hline
\end{tabular}




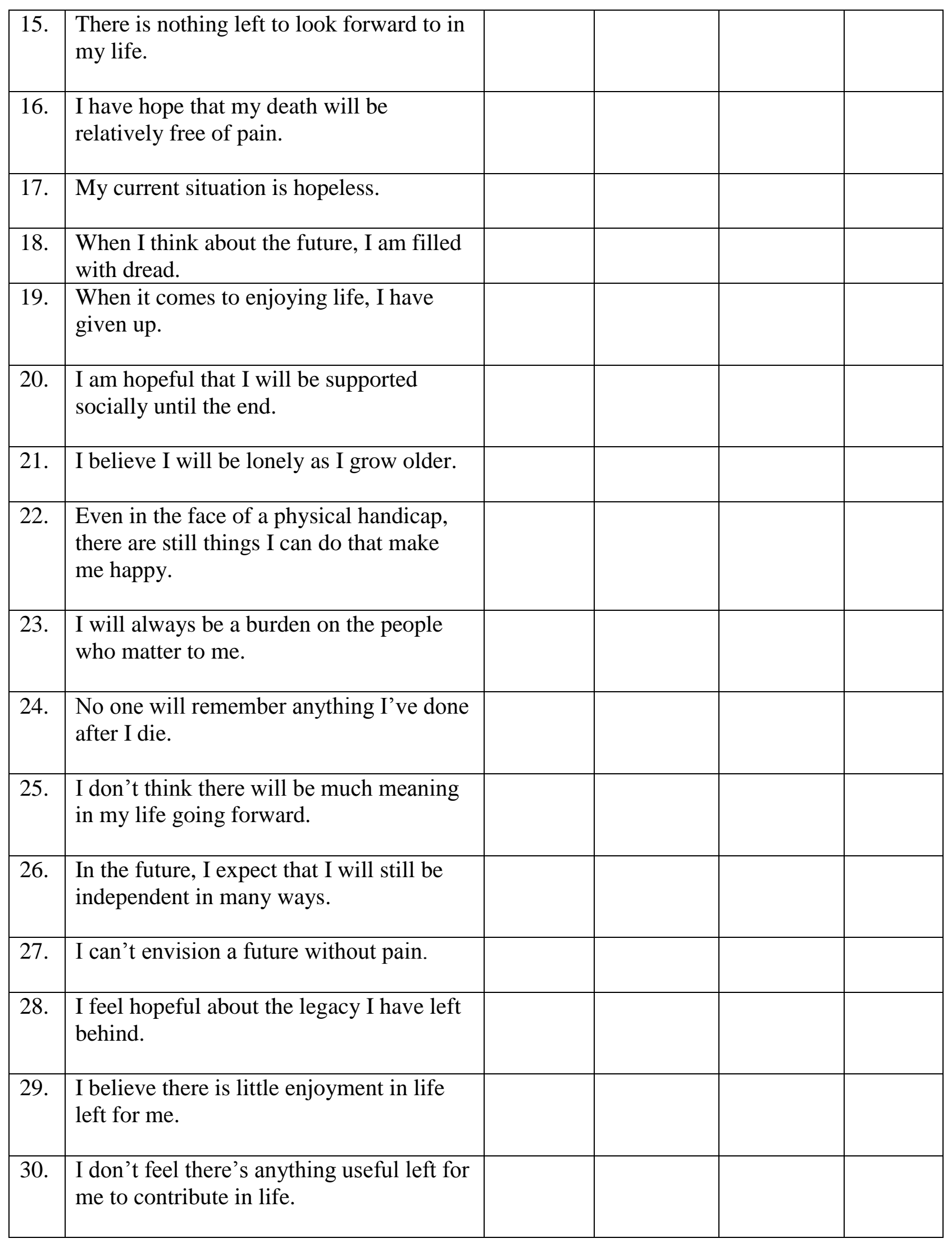


Appendix D. Beck Hopelessness Scale.

\begin{tabular}{|c|c|c|}
\hline 1. I look forward to the future with hope and enthusiasm. & True & False \\
\hline $\begin{array}{l}\text { 2. I might as well give up because I can't make things better for } \\
\text { myself. }\end{array}$ & True & False \\
\hline $\begin{array}{l}\text { 3. When things are going badly, I am helped by knowing they can't } \\
\text { stay that way forever. }\end{array}$ & True & False \\
\hline 4. I can't imagine what my life would be like in 10 years. & True & False \\
\hline 5. I have enough time to accomplish the things I most want to do. & True & False \\
\hline 6. In the future, I expect to succeed in what concerns me most. & True & False \\
\hline 7. My future seems dark to me. & True & False \\
\hline $\begin{array}{l}\text { 8. I expect to get more of the good things in life than the average } \\
\text { person. }\end{array}$ & True & False \\
\hline $\begin{array}{l}\text { 9. I just don't get the breaks, and there's no reason to believe I will } \\
\text { in the future. }\end{array}$ & True & False \\
\hline 10. My past experiences have prepared me well for my future. & True & False \\
\hline $\begin{array}{l}\text { 11. All I can see ahead of me is unpleasantness rather than } \\
\text { pleasantness. }\end{array}$ & True & False \\
\hline 12. I don't expect to get what I really want. & True & False \\
\hline $\begin{array}{l}\text { 13. When I look ahead to the future, I expect I will be happier than } \\
\text { I am now. }\end{array}$ & True & False \\
\hline 14. Things just won't work out the way I want them to. & True & False \\
\hline 15. I have great faith in the future. & True & False \\
\hline 16. I never get what I want so it's foolish to want anything. & True & False \\
\hline $\begin{array}{l}\text { 17. It is very unlikely that I will get any real satisfaction in the } \\
\text { future. }\end{array}$ & True & False \\
\hline 18. The future seems vague and uncertain to me. & True & False \\
\hline 19. I can look forward to more good times than bad times. & True & False \\
\hline
\end{tabular}


20. There's no use in really trying to get something I want because True False I probably won't get it. 
Appendix E. Geriatric Depression Scale- Short Form.

Choose the best answer for how you have felt over the past week:

1. Are you basically satisfied with your life? YES / NO

2. Have you dropped many of your activities and interests? YES / NO

3. Do you feel that your life is empty? YES / NO

4. Do you often get bored? YES / NO

5. Are you in good spirits most of the time? YES / NO

6. Are you afraid that something bad is going to happen to you? YES / NO

7. Do you feel happy most of the time? YES / NO

8. Do you often feel helpless? YES / NO

9. Do you prefer to stay at home, rather than going out and doing new things? YES / NO

10. Do you feel you have more problems with memory than most? YES / NO

11. Do you think it is wonderful to be alive now? YES / NO

12. Do you feel pretty worthless the way you are now? YES / NO

13. Do you feel full of energy? YES / NO

14. Do you feel that your situation is hopeless? YES / NO

15. Do you think that most people are better off than you are? YES / NO 
Appendix F. Suicide Behaviors Questionnaire-Revised.

SBQ-R. In the previous sections, we have asked about some of your general thoughts and behaviors. The following questions ask about a specific topic- whether you have ever thought about suicide. Many people have had thoughts of suicide. Please answer honestly. Your responses will be kept confidential.

Note: A list of mental health agencies available to help individuals having thoughts of suicide is included at the end of the survey.

\section{Please circle one.}

1. Have you ever thought about or attempted to kill yourself?
a. Never
b. It was a brief passing thought
c. I have had a plan at least once to kill myself but I did not want to try it
d. I have attempted to kill myself, but did not want to die
e. I have had a plan at least once to kill myself and really wanted to die
f. I have attempted to kill myself, and really hoped to die

2. How often have you thought about killing yourself in the past year?
a. Never
b. Rarely (1time)
c. Sometimes (2 times)
d. Often (3-4 times)
e. Very often ( 5 or more times)

3. Have you ever told someone that you were going to commit suicide, or that you might do it?
a. No
b. Yes, at one time, but did not really want to die
c. Yes, at one time, and really wanted to die
d. Yes, more than once, but did not want to do it
e. Yes, more than once, and really wanted to do it

4. How likely is it that you will attempt suicide someday?
a. Never
b. No chance at all
c. Rather unlikely
d. Unlikely
e. Likely
f. Rather Likely
g. Very likely 
Appendix G. Duke Social Support Index- Satisfaction Subscale.

DSSI

Satisfaction sub-scale

Please circle the best answer.

1. Does it seem that your family and friends (i.e. people who are important to you) understand you?

Hardly ever Some of the time Most of the time

2. Do you feel useful to your family and friends (i.e. people important to you)?

Hardly ever Some of the time Most of the time

3. Do you know what is going on with your family and friends?

Hardly ever Some of the time Most of the time

4. When you are talking with your family and friends, do you feel you are being listened to?

Hardly ever Some of the time Most of the time

5. Do you feel you have a definite role (place) in your family and among your friends?

Hardly ever Some of the time Most of the time

6. Can you talk about your deepest problems with at least some of your family and friends?

Hardly ever Some of the time Most of the time 
Appendix H. Geriatric Anxiety Inventory- Short Form.

Please circle the response that best describes how you have felt in the past week:

\begin{tabular}{|l|c|c|}
\hline 1. I worry a lot of the time. & Agree & Disagree \\
\hline 2. Little things bother me a lot. & Agree & Disagree \\
\hline 3. I think of myself as a worrier. & Agree & Disagree \\
\hline 4. I often feel nervous. & Agree & Disagree \\
\hline 5. My own thoughts often make me feel nervous. & Agree & Disagree \\
\hline
\end{tabular}


Appendix I. Interpersonal Needs Questionnaire- Perceived Burdensomeness Subscale

The following questions ask you to think about yourself and other people. Please respond to each question by using your own current beliefs and experiences, NOT what you think is true in general, or what might be true for other people. Please base your responses on how you've been feeling recently. Use the rating scale to find the number that best matches how you feel and write your response next to the item. There are no right or wrong answers: we are interested in what you think and feel.

1

Not at all true for me
2
4

Somewhat

true for me
6 7

Very True for me

1. These days, the people in my life would be better off if I were gone.

2. These days, the people in my life would be happier without me.

3. These days, I think I am a burden on society.

4. These days, I think my death would be a relief to the people in my life.

5. These days, I think the people in my life wish they could be rid of me.

6. These days, I think I make things worse for the people in my life. 
Appendix J. Marlowe-Crowne Social Desirability Scale- Revised.

Listed below are a number of statements concerning personal attitudes and traits. Read each item and decide whether the statement is true or false as it pertains to you.

\begin{tabular}{|l|c|c|}
\hline 1. I have never intensely disliked someone. & True & False \\
\hline 2. I sometimes feel resentful when I don't get my way. & True & False \\
\hline $\begin{array}{l}\text { 3. There have been times when I felt like rebelling against people } \\
\text { in authority even though I knew they were right. }\end{array}$ & True & False \\
\hline $\begin{array}{l}\text { 4. I am always courteous, even to people who are disagreeable. } \\
\text { 5. There have been times when I was quite jealous of the good } \\
\text { fortune of others. }\end{array}$ & True & False \\
\hline 6. I am sometimes irritated by people who ask favors of me. & False \\
\hline
\end{tabular}


Appendix K. Common health problems checklist.

Please indicate which conditions you have by circling YES or NO.

\begin{tabular}{|l|cc|}
\hline \multicolumn{1}{|c|}{ Condition } & \multicolumn{2}{|c|}{ Do you have this health condition? } \\
\hline Arthritis & Yes No \\
\hline Heart trouble & Yes & No \\
\hline Depression & Yes & No \\
\hline High Blood Pressure & Yes & No \\
\hline Diabetes & Yes & \\
\hline Anxiety & Yes & No \\
\hline Cancer & Yes & No \\
\hline Obesity & Yes \\
\hline Breathing Problems & Yes & Yes \\
\hline Back Problems & & \\
\hline
\end{tabular}




\section{Appendix L.}

HILL-S

Please rate how much you agree or disagree with each statement at the present time.

\begin{tabular}{|l|l|l|l|l|l|}
\hline No. & Item & Disagree & $\begin{array}{c}\text { Somewhat } \\
\text { Disagre }\end{array}$ & $\begin{array}{c}\text { Somewhat } \\
\text { Agree }\end{array}$ & Agree \\
\hline 1. & $\begin{array}{l}\text { I feel powerless to make changes in my } \\
\text { life. }\end{array}$ & & & & \\
\hline 5. & $\begin{array}{l}\text { If my health significantly declines, I } \\
\text { will have no reason to go on. }\end{array}$ & & & & \\
\hline 7. & $\begin{array}{l}\text { I doubt that my current situation will } \\
\text { ever improve. }\end{array}$ & & & & \\
\hline 9. & $\begin{array}{l}\text { The process of dying will be } \\
\text { unbearable. }\end{array}$ & & & & \\
\hline 10. & $\begin{array}{l}\text { When times are tough, I know they } \\
\text { can't stay that way forever. }\end{array}$ & & & & \\
\hline 11. & $\begin{array}{l}\text { Even in my later life, I can be useful } \\
\text { and helpful to others. }\end{array}$ & & & & \\
\hline 17. & My current situation is hopeless. & & & & \\
\hline 21. & $\begin{array}{l}\text { I believe I will be lonely as I grow } \\
\text { older. }\end{array}$ & & & & \\
\hline 22. & $\begin{array}{l}\text { Even in the face of a physical handicap, } \\
\text { there are still things I can do that make } \\
\text { me happy. }\end{array}$ & & & & \\
\hline 23. & $\begin{array}{l}\text { I will always be a burden on the people } \\
\text { who matter to me. }\end{array}$ & & & & \\
\hline 26. & $\begin{array}{l}\text { In the future, I expect that I will still be } \\
\text { independent in many ways. }\end{array}$ & & & & \\
\hline left for me. & & & & \\
\hline 27. & & & & \\
\hline
\end{tabular}

